\title{
Insights into I-motif stabilization by high resolution primer extension assays: Its
}

\section{strengths and limitations}

Jan Jamroskovic ${ }^{1 \#}$, Marco Deiana ${ }^{1}$, and Nasim Sabouri. ${ }^{1 \#}$

${ }^{1}$ Department of Medical Biochemistry and Biophysics, Umeå University, 90187 Umeå, Sweden

\# Co-corresponding authors

ORCID:

Jan Jamroskovic: 0000-0001-6871-7663

Marco Deiana: 0000-0002-7815-4494

Nasim Sabouri: 0000-0002-4541-7702 


\begin{abstract}
Cytosine-rich DNA can fold into four-stranded intercalated structures, i-motif (iM), in acidic pH and require hemi-protonated $\mathrm{C}: \mathrm{C}^{+}$base pairs to form. However, its formation and stability rely on many other factors that are not yet fully understood. In here, we combined biochemical and biophysical approaches to determine the factors influencing iM stability in a wide range of experimental conditions. By using high resolution primer extension assays, circular dichroism and absorption spectroscopies, we demonstrate that the stability of three different biologically relevant iMs are not dependent on molecular crowding agents. Instead, some of the crowding agents affected overall DNA synthesis. We also tested a range of small molecules to determine their effect on iM stabilization at physiological temperature, and demonstrated that the G-quadruplex-specific molecule, CX-5461, is also a promising candidate for selective iM stabilization. This work provides important insights into the requirements needed for different assays to accurately study iM stabilization, which will serve as important tools for understanding iMs' biological roles and their potential as therapeutic targets.
\end{abstract}




\section{Introduction}

An important characteristic of the DNA molecule is its ability to form not only double-stranded DNA structures but also non-canonical DNA structures. Among these structures, cytosine-rich imotif DNA structures (iM) were first identified in vitro in 1993 (Gehring et al., 1993), and many years later their formation in human nuclei was visualized by an iM-specific antibody (iMab) (King et al., 2020; Zeraati et al., 2018). Sequences that form iMs are for instance enriched in promoters of oncogenes such as BCL2, KRAS and MYC, and iM formations in these sites are suggested to act as molecular switches to control gene expression and to be modulated by small molecules (Kaiser et al., 2017; Kang et al., 2014; Kendrick et al., 2014; Sutherland et al., 2016).

iMs are formed in C-rich ssDNA by hydrogen bonding between hemi-protonated cytosines $\left(\mathrm{C}: \mathrm{C}^{+}\right)$. The $\mathrm{pK}_{\mathrm{a}}$ of $\mathrm{N} 3$ position of the cytosine is $\sim 4.5$ (Mergny et al., 1995), but other factors as characteristic DNA sequence and the length and number of cytosine tracts influence the formation and stability of $\mathrm{iM}$ in higher $\mathrm{pH}$ (Gurung et al., 2015; Wright et al., 2017). Also, chemicals and physical environmental factors have strong influence on iM formation. The most important factor is so far the $\mathrm{pH}$ of the environment, in which $\mathrm{iM}$ formation is heavily dependent on. Only slight $\mathrm{pH}$ changes affect iM folding and stability (Cheng et al., 2021a; Cheng et al., 2021b; Mergny et al., 1995). Other factors, such as temperature, ionic strength and crowding conditions have also positive/negative impact on the stability of the iM. Higher temperature and ionic strength cause iM destabilization, while crowding conditions favour their formation and increase stability (Dzatko et al., 2018; Mergny et al., 1995; Nguyen et al., 2017; Rajendran et al., 2010; Takahashi et al., 2017). Thus, mimicking the complex cellular milieu in vitro helps to accurately study iM, but all aforementioned factors must be strictly controlled for.

To characterize an iM structure and its folding, methods like ultraviolet (UV) absorption, nuclear magnetic resonance (NMR), and circular dichroism (CD) spectroscopies are widely used 
to record the typical iM spectral signature. The important parameter called $\mathrm{pH}_{\mathrm{T}}$ (transition $\mathrm{pH}$ ) is usually used to characterise iMs. It is defined as $\mathrm{pH}$ in which $50 \%$ of $\mathrm{iM}$ is folded at given temperature. Therefore, different iMs have different $\mathrm{pH}_{\mathrm{T}}$ values that are determined experimentally by for instance absorption or CD measurements.

To reconstitute DNA replication in vitro, primer extension assay is commonly used. This experimental system consists of several components: i/ DNA template containing iM DNA sequence of interest with annealed fluorescently/radioactively labelled primer, ii/ DNA polymerase used to synthesize over the iM structure, iii/ dNTPs as DNA building blocks, iv/ $\mathrm{Mg}^{2+}$ cofactor and $\mathrm{Na}^{+}$or $\mathrm{K}^{+}$salts, and $\mathrm{v} / \mathrm{BSA}$ protein to avoid unspecific binding of DNA polymerase. Other additives as molecular crowders, or small molecules can be supplemented and their effect on iMs stability can be studied via DNA synthesis. The principle of the assay is to follow the extension of a labelled primer during DNA synthesis when annealed to a template DNA that can form different structures. Any disturbance/blockage during the synthesis will cause pausing/arresting of the DNA polymerase and eventually resulting in falling off the template and thus formation of shorter products than the full-length products. These products are separated on a denaturing polyacrylamide gel and later visualized (Scheme 1). Primer extension assays to study the stability of iMs was earlier reported by the Sugimoto lab. They showed that a fragment of the E. coli DNA polymerase II (Klenow fragment) pauses while replicating DNA containing iM-forming sequence (Takahashi et al., 2017). Various molecular crowders and co-solutes were used to mimic crowding effects of the cell inner environment, and thus achieve comparable conditions in vitro. $\mathrm{pK}_{\mathrm{a}}$ of iMs was reported to be shifted under crowding conditions into neutral $\mathrm{pH}=7.0$ and above. Another primer extension study was performed by the Muniyappa group where it was found that the DNA polymerase is paused at an iM-forming sequence from S. cerevisiae when treated by singlewalled carbon nanotubes (SWNT), suggesting iMs pKa shift and stabilization in $\mathrm{pH}=7.5$ (Kshirsagar et al., 2017). 
In here, we employed high-resolution primer extension assay to step-wise monitor DNA synthesis in iM-containing templates. The products from the primer extension assay were separated on high resolution sequencing gels, which allowed us to follow DNA synthesis in one nucleotide steps over time in various conditions. When combined with proper controls, highresolution primer extension assays are very informative, and the large sized sequencing gels allow running more than 50 samples in one gel which is advantageous when testing a number of various conditions, drugs and time points. For these assays, we selected some of the most stable iMs, which are reported to fold in neutral/basic $\mathrm{pH}$ and we tested their $\mathrm{pH}$ stability upon addition of co-solutes and molecular crowders (glycerol, PEG1000, PEG8000, dextran40 or ficol70), and upon treatment with various G4-stabilizing compounds. Furthermore, we have validated the primer extension assays with classical spectroscopic methods (absorption, CD, and NMR). Because iMs are highly dependent on the slight changes of $\mathrm{pH}$, we paid special attention to carefully measure $\mathrm{pH}$ in all experiments, repeatedly. Every small change of $\mathrm{pH}$ was corrected and re-measured, especially when using different additives in high concentrations. Surprisingly, we did not detect any $\mathrm{pK}_{\mathrm{a}}$ shifts into neutral $\mathrm{pH}$ in any of the used conditions and $\mathrm{iM}$ templates regardless of methods used (absorption, CD, NMRs, or primer extension assay). Moreover, we did not identify any iM destabilization in the primer extension assay that are caused by G4-ligands, instead we identified compound CX-5461 as a very potent iM stabilizer.

\section{Results and discussion}

\section{Rapid unfolding of iM structures in pH titration.}

The iM-forming sequences, Jazf1, Dap and Hif-1 $\alpha$ are present in the promoter regions of the JAZF1 (JAZF Zinc Finger 1), DAP (Death-associated Protein 1) and HIF1- $\alpha$ (Hypoxia Inducible Factor 1A) genes. Jazf1 protein is a key transcriptional regulator of ribosome biogenesis and insulin translation, and it is associated to prostate cancer and endometrial stromal tumors (Kobiita 
et al., 2020; Koontz et al., 2001; Thomas et al., 2008). Dap and Hif-1 $\alpha$ are also associated to cancer and correlate with metastasis of breast cancer (Ebright et al., 2020; Wazir et al., 2015). All three iM-forming sequences were earlier reported to be stable at neutral and basic $\mathrm{pH}$, (Dzatko et al., 2018; Takahashi et al., 2017; Wright et al., 2017). However, a more recent study conducted in the Mergny lab did not confirm previously published $\mathrm{pH}_{\mathrm{T}}$ values and showed that Dap and Hif$1 \alpha$ are unstable at physiological conditions (pH 7.0) (Cheng et al., 2021a).

To investigate the reason of these discrepancies between the published reports and to determine the stability of these iMs, we first employed spectroscopic techniques (CD, UV absorption, and ${ }^{1} \mathrm{H}$ NMR) to measure iM folding at $25{ }^{\circ} \mathrm{C}$. It is known that iMs are highly dependent on the environmental $\mathrm{pH}$ and minor changes might have immediate effect on the structure formation, therefore we paid extra care for the selection of buffer, ionic strength (Mergny et al., 1995), and temperature in our measurements. We selected MES buffer with pKa at 6.21 because the buffer range is suited for iM studies, and it is widely used in the field of non-B DNA research. Furthermore, throughout the whole study, the ionic strength was calculated and maintained with $\mathrm{KCl}$ at the constant level of $145 \mathrm{mM}$. To confirm the correct $\mathrm{pH}$ of each sample, $\mathrm{pH}$ was measured immediately before and after recorded CD and absorption spectra. Recorded CD spectra in $\mathrm{pH}=5.4$ showed characteristic spectral signatures for $\mathrm{iM}$ formation with a positive peak signal at $288 \mathrm{~nm}$ and a negative peak at $255 \mathrm{~nm}$ for all three IM sequences (Figure S1). When increasing $\mathrm{pH}$ from 5.4 to higher $\mathrm{pH}$, the $\mathrm{CD}$ peak at $288 \mathrm{~nm}$ decreased, and a clear transition between iM and non-iM DNA was observed through the characteristic formation of a well-defined isodichroic point centred at $276.5 \mathrm{~nm}$. Similarly, the absorption band at $295 \mathrm{~nm}$ decreased with increasing $\mathrm{pH}$ (Figure S1). Changes of $\mathrm{CD}_{\max }(\mathrm{CD}$ peak at $276-288 \mathrm{~nm})$ and $\mathrm{Abs}_{295}$ were plotted against $\mathrm{pH}$ to determine the $\mathrm{pH}_{\mathrm{T}}$ values (Figure 1 and $\mathrm{S} 2$ ). Unfolding curves clearly showed two slopes, suggesting heterogenous formation of different iM structures in different $\mathrm{pH}$. The slope was less steep in lower $\mathrm{pH}$, but after a critical value the slope became steeper, and the structure unfolded 
quickly. Therefore, two $\mathrm{pH}_{\mathrm{T}}$ values were calculated by fitting the data into bi-dose response function (Figure S2). For simplification, also one overall $\mathrm{pH}_{\mathrm{T}}$ was determined by fitting the data into a single dose-response function (Figure 1). The 1D ${ }^{1} \mathrm{H}$ NMR spectra for all three sequences showed the characteristic iM signals around 15-16 ppm at $\mathrm{pH}=6$ or lower, which disappeared at $\mathrm{pH}=7.2$ (Figure 1C), confirming our observed analysis by CD and UV absorption (Figure 1A-C). In summary, all three sequences folded into iMs, however, none of them were stable at $\mathrm{pH}=7.0$ or higher, which is in agreement with studies conducted by the Mergny lab (Cheng et al., 2021a).

Next, we examined iM formation during in vitro DNA replication in primer extension assays at $37^{\circ} \mathrm{C}$ (Han et al., 1999b). For this assay, the different DNA templates containing iM-forming sequences were annealed to a fluorescently labelled DNA primer. The final templates consist of dsDNA part following by 10 nucleotide ssDNA linker to ensure no steric interference between the DNA polymerase and the folded iM (Scheme 1). Ionic strength was kept constant at $145 \mathrm{mM}$ in all reaction conditions by addition of $\mathrm{KCl}$, and the $\mathrm{pH}$ was measured by a microprobe to ensure correct $\mathrm{pH}$ of the reaction environment. For the primer extension assay, we used all three iMsequences, Jazf1, Dap and Hif-1 $\alpha$, and a non-iM forming control sequence, which was derived from S. pombe genome. To be able to follow the whole process of DNA synthesis in all reactions with different $\mathrm{pH}$, samples were collected over 40 minutes, and visualized on $10 \%$ denatured polyacrylamide sequencing gel which allows $1 \mathrm{nt}$ resolution of the newly synthesized DNA.

Despite of the decreased polymerase activity in pH below 6 (Richard et al., 2006), the amount of pausing signal can still be attributed to the stability of the $\mathrm{iM}$ in various $\mathrm{pH}$. We observed strong pausing right before an iM-forming sequence already after $0.5 \mathrm{~min}$ of the reaction in $\mathrm{pH}=5.6$ with all three templates. For the Jazf1 template, two pausing regions were detected. The first region was at nucleotide 10 , just before the start of the C-rich iM sequence. With progression of time, pausing was also detected at $11^{\text {th }}$ and $12^{\text {th }}$ position, suggesting that the JazF1 $\mathrm{iM}$ slows/pauses DNA synthesis, but that continuous reloading of the polymerase allows bypassing of the iM. The second pausing site was observed at the $3^{\text {rd }} \mathrm{C}$-tract, suggesting that another type 
of iM folding or an alternative type of structure may be present. The pausing sites were reduced during the time course of the reactions, however still some pausing was detected even after 40 minutes. With increasing $\mathrm{pH}$ and time of the reaction, the pausing sites were less pronounced, and finally no pausing sites were detected after $0.5 \mathrm{~min}$ in $\mathrm{pH}=6.4$, resulting in maximum fulllength products almost immediately after the start of the reaction (Figure 2 and S3). Similar observations were made with Dap and Hif-1 $\alpha$ templates, but these iMs were fully bypassed without any detectable pausing already at $\mathrm{pH}=6.2$. Similar additional pausing site as Jazf1 before the second C-tract was observed in the Dap template, but not in the Hif-1 $\alpha$ template (Figure S4, S5). Control reactions with non-iM DNA template did not show specific pausing sites, but an overall slower DNA synthesis at $\mathrm{pH}=6$ and lower (Figure S6), which agrees with previous reports (Richard et al., 2006). To quantify stability of iMs during DNA synthesis in primer extension assay, maximum pausing signal from individual reactions was plotted over the $\mathrm{pH}$ and $\mathrm{pH}_{\mathrm{T}}$ values were calculated representing 50\% iM stability (Figure 2E). $\mathrm{PH}_{\mathrm{T}}$ values of Dap and Hif-1 $\alpha$ were 6.0 and they were fully unfolded in $\mathrm{pH}=6.2$ and $\mathrm{pH}_{\mathrm{T}}$ for Jazf1 was 6.2 and fully unfolded in $\mathrm{pH}=6.4$. The stability of the iM structures in the primer extension assays showed a similar steep slope as unfolding in $\mathrm{CD}$ and absorption $\mathrm{pH}$ titration experiments. Jazf1 showed the best stability in the given $\mathrm{pH}$ and had the best resolution for detection of pausing during the course of the primer extension reaction.

\section{Molecular crowders and co-solutes do not shift the $\mathrm{pK}_{\mathrm{a}}$ of $\mathrm{iMs.}$}

It is reported that molecular crowders and co-solutes shift the $\mathrm{pK}_{\mathrm{a}}$ of $\mathrm{N} 3$ in the cytosine base leading to increased stabilization of iMs in higher pH (Bhaysar-Jog et al., 2014; Rajendran et al., 2010; Takahashi et al., 2017). Polyethylene Glycol (PEG) are used as the main preference for those experiments, however a clear mechanism of how PEGs act on iMs remains unknown. Generalization of these phenomena led us to investigate the possible effects of co-solutes and 
crowders on the $\mathrm{pK}_{\mathrm{a}}$ shift of Jazf1 and Hif-1 $\alpha$ iMs. Therefore, we recorded CD spectra of iMs supplemented with $20 \%$ (v/v) of glycerol, PEG1000 or $20 \%(\mathrm{w} / \mathrm{v})$ of PEG8000, dextran40 or ficoll70. The current $\mathrm{pH}$ of each sample was confirmed before and after each recorded CD spectrum. $C D_{\max }$ at $288 \mathrm{~nm}$ and transition to ssDNA and $276.5 \mathrm{~nm}$ was not affected by any of the tested additives (Figure S7 and S8). Next, we plotted $\mathrm{CD}_{\max }$ over $\mathrm{pH}$ and calculated the $\mathrm{pH}_{\mathrm{T}}$ values (Figure 1C, D). All $\mathrm{pH}_{\mathrm{T}}$ values in the presence or absence of additives were in the range of $6.7 \pm$ 2SD for both Jazf1 and Hif-1 $\alpha$ iMs. Addition of glycerol affected $\mathrm{pH}_{\mathrm{T}}$ slightly more, $\mathrm{pH}_{\mathrm{T}}$ of Jazf1 and Hif-1 $\alpha$ was 6.45 and 6.41 , respectively. Overall, differences in $\mathrm{pH}_{\mathrm{T}}$ values were very subtle, suggesting that neither of these agents shifts the $\mathrm{pK}_{\mathrm{a}}$ of the tested iM sequences to neutral values.

\section{Molecular crowders and co-solutes do not cause selective replication fork blockage at the}

iM.

Since we did not detect a shift of iMs $\mathrm{pK}_{\mathrm{a}}$ to neutral $\mathrm{pH}$ in our $\mathrm{CD}$ measurements, we instead tested the hypothesis that iMs in crowding conditions are stabilized and hence enhance the pausing of the DNA polymerase before the iM. We selected Jazf1, the most stable iM, and performed primer extension assays at $\mathrm{pH}=6.0$. The processivity of the polymerase at $\mathrm{pH}=6.0$ was not strongly affected in this assay. Neither was primer consumption affected and no random pausing was observed in the control reaction (Figure S6). We performed reactions supplemented with $20 \%(\mathrm{v} / \mathrm{v})$ of glycerol, PEG1000 or $20 \%(\mathrm{w} / \mathrm{v})$ of PEG8000, dextran40 or ficoll70. Some of the additives affected $\mathrm{pH}$, therefore the composition (basic and acidic part of the buffer) of each reaction was recalculated, and $\mathrm{pH}$ was adjusted to $\mathrm{pH}=6.00 \pm 0.05$. lonic strength was again kept constant at $145 \mathrm{mM}$ by addition of $\mathrm{KCl}$ (Figure 3 and Figure S9). The pausing sites in Jazf1 template on the position 10,11 and 12 detected in the buffer only control after 0.5 min, was also detected in the presence of glycerol, dextran40, and ficoll70. When reaction progressed, pausing at $12^{\text {th }}$ nucleotide remained visible during the first five minutes, but the iM was fully bypassed after 
10 minutes. PEG1000 caused pausing in the linker region as well and the primer was not extended enough to reach the $\mathrm{iM}$ in the first $0.5 \mathrm{~min}$. Therefore, pausing was detected at later time points. In these reactions, the primers were fully consumed only after three minutes of reaction. PEG8000 also inhibited the start of the reaction, and most of the primer was not utilized by the polymerase even after 40 min of reaction (Figure S9). On the other hand, CD peaks at 288 nm were not affected by the different PEGs or the other additives (Figure 1D). Therefore, slower replication by PEGs suggest potential inhibition through the binding of the polymerase to the primer-template, instead of selective iM stabilization. Alternatively, it decreases the processivity of the polymerase or precipitate the polymerase. Furthermore, only $20 \%$ maximum pausing signal was detected in the PEG1000 sample compared to $45 \% \pm 5$ in all the other reactions (Figure $3 G$ ).

Both the synthesis of the full-length product and the decreased pausing signal were plotted over time, and exponential equations were used to mathematically fit the data. Apparent rate constants for a particular reaction were derived for the synthesis of full-length product $\left(\mathrm{k}_{\mathrm{F}}\right)$ and for the decay of a pausing signal $\left(k_{p}\right)$. We compared $k_{F}$ and $k_{p}$ among all the tested conditions (Figure $3 E, F)$. All additives increased both $k_{F}$ and $k_{P}$ values compared to a control reaction suggesting faster progression (processivity) of the polymerase, but neither stabilizing nor destabilizing effect of the Jazf1 iM was observed. These results were also observed with the Dap and Hif1- $\alpha$ templates (Figure S11 and S12).

Reaction supplemented with PEG1000 had a peculiar behaviour. The primer was utilized slower, the pausing sites were detected later in the reaction and the maximum pausing signal was also decreased, but $\mathrm{k}_{\mathrm{F}}$ and $\mathrm{k}_{\mathrm{P}}$ were higher than in the control with no additives. As shown above, CD spectra from pH titrations were not affected by PEG1000. So, this behaviour is caused by affecting the binding of the DNA polymerase to DNA or its processivity. This effect was even more pronounced by PEG8000.

\section{CX-5461 stabilizes iMs in primer extension assay}


Earlier reports have shown that some G4 ligands also bind iMs, and even cause iM destabilization (Abdelhamid et al., 2019; Pagano et al., 2018). Therefore, we examined the stabilization/destabilization behavior of a few ligands in our high-resolution primer extension assay. We anticipated that compounds which destabilize iM will facilitate DNA synthesis over iM by decreasing polymerase pausing, on the other hand compounds stabilizing iM will enhance polymerase pausing before the iM. We tested various concentrations of G4 ligands including: TmPyP4 (Han et al., 1999a), PhenDC3 (Chung et al., 2014), pyridostatin (Rodriguez et al., 2008), CX-5461 (Xu et al., 2017), CX-3543 (Drygin et al., 2009), Braco19 (Read et al., 2001), and quinazoline $8 \mathrm{~g}$ (Jamroskovic et al., 2020). We also used the iM stabilizer, ellipticine-based NSC71795 (King et al., 2020) as a positive control and the DNA intercalator, BMH-21 (Peltonen et al., 2010) as a negative control. The concentration range used in the experiments was optimized for each compound. We selected the most stable iM Jazf1 and ran primer extension reaction in $\mathrm{pH}=6$ for four minutes. After four minutes, pausing sites at the $\mathrm{iM}$ is still clearly visible (20-30\% of fluorescence signal) (Figure $2 \mathrm{~B}-\mathrm{gel} \mathrm{pH}=6$ ), and allows us to follow both stabilization and destabilization effects of the iM by the ligands. None of the ligands facilitated DNA replication passed the iM by destabilizing the structure, as the pausing sites in all reactions had similar intensity. However, in high concentrations many of the compounds affected replication in an unspecific manner by interfering with DNA synthesis. This included, NSC71795 that unspecifically affected both, iM and non-iM templates (Figure S12 and S13). Only two compounds CX-5461 and Braco19 caused increased pausing of the DNA polymerase close to the iM structure position at $\mathrm{pH}=6$. Moreover, $\mathrm{CX}-5461$ did not affect replication over non-iM DNA even at $50 \mu \mathrm{M}$ concentration, but Braco19 affected iM and Non-iM DNA replication at $25 \mu \mathrm{M}$. We selected both these compounds for more in detail examination and tested their stabilizing potential in various pHs with three different templates, Jazf1, Hif-1 $\alpha$ and non-iM (Figure 4). Here, we decreased the time of reaction to 1 minute to be able to follow maximum polymerase pausing, which occurred in 
the beginning of the reaction. After one minute, we observed pausing at nucleotides 10,11 and 12 on the Jazf1 template (Figure 2B-gel $\mathrm{pH}=6$ ) and at nucleotides 14 and 15 on the Hif- $1 \alpha$ template (Figure S5). In DMSO-treated reaction, these pausing sites disappeared with increasing $\mathrm{pH}$, firstly at nucleotides 10 and 11 of Jazf1 at $\mathrm{pH}=6$. At $\mathrm{pH}=6.4$, pausing was not detected. Similarly, both pausing sites at nucleotides 14 and 15 of Hif $1 \alpha$ template disappeared quickly with increasing $\mathrm{pH}$. CX-5461 enhanced the pausing of the DNA polymerase on nucleotides 10, 11 and 12 of Jazf1 template until $\mathrm{pH}=6.2$. Similarly, $\mathrm{CX}-5461$ stabilized Hif- $1 \alpha$ iM in $\mathrm{pH}=5.8$ and 6.0 , but pausing was dramatically decreased at $\mathrm{pH}=6.2$.

For the Braco19-treated reactions, a new strong pausing site at nucleotide 9 in the Jazf1 template was detected and pausing was still visible at $\mathrm{pH}=6.4$. In the $\mathrm{Hif}-1 \alpha$ template, pausing at nucleotides 11 and 12 was very strong and persisted throughout all $\mathrm{pHs}$ until $\mathrm{pH}=7.2$. But replication of the non-iM template was also strongly affected, with little amount of full-length products due to several pausing sites between nucleotides 8-14. This effect on the non-iM template was not visible after the four minutes reaction (Figure S13) due to continues recycling by the DNA polymerase that was allowed during the longer reaction time. Formation of additional pausing sites in the presence of Braco19 on Hif-1 $\alpha$ template suggests that Braco19 binds other types of non-iM structures and causes polymerase pausing, and therefore can be attributed to a false positive result, and not to inducing iM stabilization. ${ }^{1} \mathrm{H}$ NMR spectra of Hif-1 $\alpha$ DNA showed two peaks, one characteristic for $\mathrm{iM}$ at 15-16 ppm and second peak characteristic for WatsonCrick base pairing at $13 \mathrm{ppm}$ (Figure 1C). The second peak at $13 \mathrm{ppm}$ was present throughout all tested $\mathrm{pHs}$, at $\mathrm{pH} 5.4,6.0$ and 7.2 , while the $\mathrm{iM}$ peak was not present at $\mathrm{pH}=7.2$ anymore. To determine if Braco19 binds to other types of structures, we recorded ${ }^{1} \mathrm{H}$ NMR spectra upon it's binding to Hif- $1 \alpha$ DNA. At $\mathrm{pH}=5.4$, the specific signal at 13 ppm disappeared when using equimolar concentrations of Braco-19, suggesting its interaction to the non-iM structure. Titration experiments with Braco19 were performed at $\mathrm{pH}=6.0$ and 7.2. Increased concentration of Braco- 
19 resulted in diminishing signal at $13 \mathrm{ppm}$ for both $\mathrm{pH}=6.0$ and 7.2 , supporting our hypothesis that Braco19 interacts with the non-iM structure in the Hif-1 $\alpha$ template (Figure 5). Our conclusion is also supported by observed binding of Braco19 to dsDNA (Deiana et al., 2021).

\section{Discussion}

High-resolution primer extension assay is a very valuable tool to study the effect of iMs on DNA replication. It's one nucleotide resolution allows identification of specific pausing sites and how they resolve or are bypassed in time. Primer consumption, and synthesis of the full product give additional information about the reaction. Possible confounders can be identified when all necessary controls are made, including time-resolution.

Here, we have used primer extension assay to compare $\mathrm{pH}$ stability of three different iMs and their effect on DNA polymerase. We identified polymerase secondary pausing site in Jazf1 and Dap DNA templates, which suggests heterogeneity in iM folding. We re-assessed the effects of $20 \%$ molecular crowders on the stability of iMs in primer extension assay, which was suggested by Sugimoto (Takahashi et al., 2017), but we did not confirm any stabilizing effect when using $20 \%$ crowders. Rather, PEGs affected primer consumption, and reactions were inhibited in an iMindependent manner. It was also suggested that some of the typically used G4-ligands bind to iM and destabilize them (Abdelhamid et al., 2019; Pagano et al., 2018). In that case, we anticipated that DNA replication would be facilitated upon treatment with those compounds. But majority of the compounds had no effect on the stability of the iMs, but high concentrations unspecifically affected replication of both iM and non-iM templates, which is not uncommon for small molecules. Only one of the tested compounds CX-5461 specifically stabilized iMs and non-iM replication was not affected. We believe that further examination of CX-5461 and its analogues can be very useful to identify potent iM stabilizers.

C-rich DNA sequences containing self-complementary parts may preferably use WatsonCrick base pairing to fold to an alternative structure, usually hairpins (Kaiser et al., 2017; Kang et 
al., 2014; Kendrick et al., 2014; Sutherland et al., 2016). In our case Hif-1 $\alpha$ sequence contain selfcomplementary regions on both sides, and we confirmed the existence of Watson-Crick base pairing by ${ }^{1} \mathrm{H}$ NMR. This alternative structure of Hif- $1 \alpha$ was present in neutral and basic $\mathrm{pH}$ and co-existed together with iM in lower pHs. We associated it with the polymerase pausing during Hif- $1 \alpha$ replication, which caused false positive results upon Braco19 treatment in primer extension assay.

The limitation of the high-resolution primer extension assay is that it does not measure stability of the iMs directly, rather via activity of the polymerase during DNA replication. Therefore, it is not straightforward to identify possible confounders affecting other components of the reaction. Special attention must be paid to primer consumption and to the reaction kinetics. High concentration of some additives may inhibit the reaction start and pausing will appear later in time mimicking iM stabilization, which was the case with PEGs. Another limitation, while using high concentrations of molecular crowders, is increased viscosity of the samples making it problematic to manipulate with, to resuspend and to load into the polyacrylamide gel. High concentrations of some crowders, for instance dextran40 and ficoll70, even influence the migration of the DNA into the gel. Therefore, samples must be diluted 5-20x, which might affect the limit of detection of some of fluorescent dyes used to label the primer. In our case, Tet-label was sufficient. Furthermore, low volumes of the assay make it difficult to correctly measure $\mathrm{pH}$ of the samples, hence using special $\mathrm{pH}$ microprobe for small volume is very beneficial.

Finally, adopting high-solution primer extension assay, and coupling it with other classical spectroscopic methods, for instance CD, NMR, and absoprtion allowed us to study iM stabilization in detail. This combination serves as another important tool in understanding the biological roles of iMs and their folding patterns. Mimicking cellular milieu is especially valuable to make a correct connection between in vivo (Dzatko et al., 2018; King et al., 2020; Wright et al., 2017) and 
in vitro biophysical experiments (Cheng et al., 2021a; Cheng et al., 2021b) and can answer important fundamental biochemical questions.

\section{Material and methods}

\section{$\underline{\text { Material }}$}

Lyophilized DNA molecules were purchased from Eurofins Genomics Ltd (Germany) and dissolved in deionized water according to manufacturer instructions. All DNA sequences used in the study are listed in the Supplementary information in Table S2.

$50 \%(\mathrm{v} / \mathrm{v})$ stock solutions of glycerol (MW = 92.09, MP Biomedicals, LLC), PEG1000 (MW $\approx 1000$, Sigma), and 50\% (w/v) of PEG8000 (MW $\approx 8000$, Sigma), dextran40 (MW = 40 000, TCI) and Ficoll 70 (MW = 70 000, GE Healthcare) were prepared in deionized water and stored at $4{ }^{\circ} \mathrm{C}$ in dark to prevent their degradation.

\section{Measurement of $\mathrm{pH}$}

All pH measurements were performed by pH meter Mettler Toledo Five Easy Plus (Metler Toledo). Samples with bigger volumes for CD and absorption spectroscopy were measured by DG 115SC probe (Mettler Toledo), temperature was manually set to $25^{\circ} \mathrm{C}$, all samples were incubated in $25{ }^{\circ} \mathrm{C}$ water bath (Julabo TW12). Samples with small volumes of $300 \mu \mathrm{L}$ used for primer extension assays were measured by In Lab Micro-probe ISM (Mettler Toledo) equipped with temperature probe, incubated in $37^{\circ} \mathrm{C}$ water bath (Julabo TW12) until temperature of the samples reached to at least $36^{\circ} \mathrm{C}$.

Both $\mathrm{pH}$ probes were calibrated by two-point calibration at $\mathrm{pH}=4$ and $\mathrm{pH}=7$ with freshly purchased calibration buffers (Mettler Toledo) prior to each measurement in the same temperature, volume, and container as was used to measure samples. Standard measurement error of $\mathrm{pH}$ meter referred by manufacturer was $\pm 0.005 \mathrm{pH}$ units.

\section{$\underline{\mathrm{CD} \text { and absorption measurements }}$}


For $\mathrm{CD}$ and absorption measurements, $1.4 \mu \mathrm{M}$ DNA diluted in deionized water was heated to 95 ${ }^{\circ} \mathrm{C}$ for 10 minutes and slowly cooled down overnight to room temperature to melt all possible secondary structures coming from DNA lyophilization. Next day, DNA was diluted to final concentration of $0.5 \mu \mathrm{M}$ into MES buffer. Composition of acidic and basic component of MES buffer of the specific $\mathrm{pH}$ at $25{ }^{\circ} \mathrm{C}$ was calculated using an online platform from Centre for Proteome Research, Liverpool (https://www.liverpool.ac.uk/pfg/Research/Tools/BuffferCalc/Buffer.html). Ionic strength was kept constant at $145 \mathrm{mM}$ in all samples by $\mathrm{KCl} . \mathrm{pH}$ of each sample was measured. Additives, glycerol and PEG1000 in final concentration of 20\% (v/v) and PEG8000, dextran40 and ficoll70 in 0.2 $\mathrm{mg} / \mathrm{ml}$, were added into the sample, and $\mathrm{pH}$ of each sample was re-measured. If additives changed $\mathrm{pH}$, then buffer composition was recalculated, and new samples were prepared with final $\mathrm{pH}$ required for measurement. Buffer composition was set as final when desired $\mathrm{pH}$ was within standard deviation of $\pm 0.05 \mathrm{pH}$ units.

$\mathrm{CD}$ and absorption spectra were recorded at $25{ }^{\circ} \mathrm{C}$ by Jasco $\mathrm{J}-810$ spectropolarimeter (Jasco International Co. Ltd.) using $1 \mathrm{~cm}$ path length quartz cuvette. Each spectrum was an accumulation of three scans recorded over $230-350 \mathrm{~nm}$ with an interval of $0.5 \mathrm{~nm}$ at a scan rate of $100 \mathrm{~nm} \mathrm{x}$ $\min ^{-1}$. Baseline for each measurement was corrected by subtracting the signal from sample without DNA. All spectra were smoothed in Origin Lab 2016 Software for visualisation purpose. Each sample in $\mathrm{pH}$ titration was prepared separately to control for ionic strength (145 mM). lonic strength of additives was assumed to not to be a contributing factor to ionic strength.

\section{$\underline{\text { Primer extension assay }}$}

Tet-labelled primer $(1 \mu \mathrm{M})$ was annealed to DNA templates $(1.25 \mu \mathrm{M})$ in $50 \mathrm{mM} \mathrm{KCl}$ at $95{ }^{\circ} \mathrm{C}$ for 5 minutes in aluminium heating block and slowly cooled down overnight. Annealed DNA in final concentration of $40 \mathrm{nM}$ was incubated in the buffer containing $50 \mathrm{mM}$ MES in required $\mathrm{pH}, 8 \mathrm{mM}$ $\mathrm{MgCl} 2,1 \mathrm{mg} / \mathrm{ml} \mathrm{BSA}, 0.05 \mathrm{U}$ of Klenow fragment (Thermo Scientific) and $\mathrm{KCl}$ in the final ionic 
strength of $145 \mathrm{mM}$ in each sample depending on the specific $\mathrm{pH}$. $\mathrm{pH}$ was measured multiple times in $300 \mathrm{uL}$ volume and final $\mathrm{pH}$ was determined with $\mathrm{SD}$ of $0.05 \mathrm{pH}$ units. Samples were incubated at $37^{\circ} \mathrm{C}$ in water bath for 10 minutes to equilibrate, and reactions were started by addition of $0.2 \mathrm{mM}$ dNTPs. Each reaction ran in $100 \mathrm{uL}$ volume. Samples were taken from the main reaction in designated time-points (described in each well in the sequencing gels) and transferred into a STOP solution (95\% formamide, $20 \mathrm{mM}$ EDTA, and $0.1 \%$ bromophenol blue) in 1:1 ratio. A total of 6 uL was loaded on the sequencing gel containing $10 \%$ polyacrylamide, 8 M urea, 25\% formamide, and 1× standard TBE buffer (Tris/borate/ethylenediaminetetraacetic acid). The gel was visualized with a Typhoon Scanner 9200 (GE Healthcare) at the Alexa setting of $\lambda=532 \mathrm{~nm}$ and quantified with the ImageQuant TL software (GE Healthcare). Primary pausing site was expressed as a sum of the total signal at nucleotides 10, 11 and 12 for Jazf11 template, 14 and 15 for Hif1- $\alpha$ and 10 and 11 for Dap template.

Samples containing co-solutes and molecular crowders: The final $\mathrm{pH}$ of each sample was measured to be $6.00 \pm 0.05$ after addition of co-solutes and molecular crowders: $20 \%(\mathrm{v} / \mathrm{v})$ of glycerol, PEG1000, or $0.2 \mathrm{~g} / \mathrm{ml}$ PEG8000, dextran40 and ficoll70. All primer extension reactions were run and sampled as described above.

Compound testing: All reactions were supplemented with various concentrations of small molecules: CX-3543, CX-5461, NSC71795 (ellipticine analogue), PhenDC3, pyridostatin (PDS), TmPyP4, Braco19, BMH-21 and quinazoline 8g (a kind gift from the Chorell lab, Umeå University). All concentrations are listed in the figures. 5\% DMSO was used as control reaction. Reactions ran for four minutes at $\mathrm{pH}=6.0$ in initial screening. For $\mathrm{pH}$ screening, reactions were run for one minute with $10 \mu \mathrm{M}$ CX-5461, $10 \mu \mathrm{M}$ Braco19 or 5\% DMSO.

\section{Nuclear magnetic resonance measurements}

$1 \mathrm{mM}$ iM stock solutions were prepared by adding deionized water into lyophilized DNA, heated to $95^{\circ} \mathrm{C}$ for 5 min and slowly cooled down before an experiment. An effective DNA concentration 
of $170 \mu \mathrm{M}$ was obtained by mixing DNA, $50 \mathrm{mM}$ MES buffer $\left(\mathrm{pH}=5.4,6.0\right.$ or 7.2 at $\left.25^{\circ} \mathrm{C}\right)$ and $\mathrm{KCl}$ into $154 \mathrm{mM}$ ionic strength and $10 \% \mathrm{D}_{2} \mathrm{O}$. NMR samples were prepared in $3 \mathrm{~mm}$ NMR tubes. Samples were titrated by adding small volumes of $10 \mathrm{mM}$ Braco19 solubilized in water, titration steps are described directly in the figure. All spectra were recorded at $298 \mathrm{~K}$ on a Bruker $850 \mathrm{MHz}$ Avance III HD spectrometer equipped with a $5 \mathrm{~mm} \mathrm{TCl}$ cryoprobe. Excitation sculpting was used, and 256 scans were recorded. Processing was performed in Topspin 4.1.3 (Bruker Biospin, Germany).

Data fitting

For $\mathrm{pH}_{\mathrm{T}}$ values, the middle point of the $\mathrm{pH}$ titration curves derived from $\mathrm{CD}$ and absorption measurements and from primer extension assays was obtained by fitting the data into doseresponse function. In case of expressing two slopes, data were fitted into bi-dose response function in OriginLab 2016 software and $\mathrm{pHT}_{1}$ and $\mathrm{pHT}_{2}$ was determined.

Apparent rate constants of full product synthesis $\mathrm{k}_{\mathrm{F}}$ and $\mathrm{iM}$ decay $\mathrm{k}_{\mathrm{P}}$ were obtained by fitting the data into one-phase exponential decay (ExpDec) function in OriginLab 2016 software:

$y=y_{0}+A e^{-x / t}$ from where apparent rate constant is defined as $k=1 / t_{1}$.

\section{References}

Abdelhamid, M.A.S., Gates, A.J., and Waller, Z.A.E. (2019). Destabilization of i-Motif DNA at Neutral pH by G-Quadruplex Ligands. Biochemistry 58, 245-249.

Bhaysar-Jog, Y.P., Van Dornshuld, E., Brooks, T.A., Tschumper, G.S., and Wadkins, R.M. (2014). Epigenetic Modification, Dehydration, and Molecular Crowding Effects on the Thermodynamics of iMotif Structure Formation from C-Rich DNA. Biochemistry 53, 1586-1594.

Cheng, M., Chen, J., Ju, H., Zhou, J., and Mergny, J.-L. (2021a). Drivers of i-DNA Formation in a Variety of Environments Revealed by Four-Dimensional UV Melting and Annealing. Journal of the American Chemical Society 143, 7792-7807.

Cheng, M., Qiu, D., Tamon, L., Istvankova, E., Viskova, P., Amrane, S., Guedin, A., Chen, J., Lacroix, L., Ju, H., et al. (2021b). Thermal and pH Stabilities of i-DNA: Confronting in vitro Experiments with Models and In-Cell NMR Data. Angewandte Chemie 60, 10286-10294.

Chung, W.J., Heddi, B., Hamon, F., Teulade-Fichou, M.P., and Phan, A.T. (2014). Solution structure of a Gquadruplex bound to the bisquinolinium compound Phen-DC(3). Angew Chem Int Edit 53, 999-1002. Deiana, M., Mosser, M., Le Bahers, T., Dumont, E., Dudek, M., Denis-Quanquin, S., Sabouri, N., Andraud, C., Matczyszyn, K., Monnereau, C., et al. (2021). Light-induced in situ chemical activation of a fluorescent probe for monitoring intracellular G-quadruplex structures. Nanoscale 13, 13795-13808. 
Drygin, D., Siddiqui-Jain, A., O'Brien, S., Schwaebe, M., Lin, A., Bliesath, J., Ho, C.B., Proffitt, C., Trent, K., Whitten, J.P., et al. (2009). Anticancer Activity of CX-3543: A Direct Inhibitor of rRNA Biogenesis. Cancer Res 69, 7653-7661.

Dzatko, S., Krafcikova, M., Hansel-Hertsch, R., Fessl, T., Fiala, R., Loja, T., Krafcik, D., Mergny, J.L., Foldynova-Trantirkova, S., and Trantirek, L. (2018). Evaluation of the Stability of DNA i-Motifs in the Nuclei of Living Mammalian Cells. Angew Chem Int Edit 57, 2165-2169.

Ebright, R.Y., Zachariah, M.A., Micalizzi, D.S., Wittner, B.S., Niederhoffer, K.L., Nieman, L.T., Chirn, B., Wiley, D.F., Wesley, B., Shaw, B., et al. (2020). HIF1A signaling selectively supports proliferation of breast cancer in the brain. Nature Communications 11.

Gehring, K., Leroy, J.L., and Gueron, M. (1993). A Tetrameric DNA-Structure with Protonated Cytosine.Cytosine Base-Pairs. Nature 363, 561-565.

Gurung, S.P., Schwarz, C., Hall, J.P., Cardin, C.J., and Brazier, J.A. (2015). The importance of loop length on the stability of i-motif structures. Chemical communications (Cambridge, England) 51, 5630-5632. Han, F.X.G., Wheelhouse, R.T., and Hurley, L.H. (1999a). Interactions of TMPyP4 and TMPyP2 with quadruplex DNA. Structural basis for the differential effects on telomerase inhibition. Journal of the American Chemical Society 121, 3561-3570.

Han, H., Hurley, L.H., and Salazar, M. (1999b). A DNA polymerase stop assay for G-quadruplexinteractive compounds. Nucleic Acids Res 27, 537-542.

Jamroskovic, J., Doimo, M., Chand, K., Obi, I., Kumar, R., Brannstrom, K., Hedenstrom, M., Nath Das, R., Akhunzianov, A., Deiana, M., et al. (2020). Quinazoline Ligands Induce Cancer Cell Death through Selective STAT3 Inhibition and G-Quadruplex Stabilization. Journal of the American Chemical Society 142, 2876-2888.

Kaiser, C.E., Van Ert, N.A., Agrawal, P., Chawla, R., Yang, D., and Hurley, L.H. (2017). Insight into the Complexity of the i-Motif and G-Quadruplex DNA Structures Formed in the KRAS Promoter and Subsequent Drug-Induced Gene Repression. Journal of the American Chemical Society 139, 8522-8536. Kang, H.-J., Kendrick, S., Hecht, S.M., and Hurley, L.H. (2014). The transcriptional complex between the BCL2 i-motif and hnRNP LL is a molecular switch for control of gene expression that can be modulated by small molecules. Journal of the American Chemical Society 136, 4172-4185.

Kendrick, S., Kang, H.J., Alam, M.P., Madathil, M.M., Agrawal, P., Gokhale, V., Yang, D.Z., Hecht, S.M., and Hurley, L.H. (2014). The Dynamic Character of the BCL2 Promoter i-Motif Provides a Mechanism for Modulation of Gene Expression by Compounds That Bind Selectively to the Alternative DNA Hairpin Structure. Journal of the American Chemical Society 136, 4161-4171.

King, J.J., Irving, K.L., Evans, C.W., Chikhale, R.V., Becker, R., Morris, C.J., Martinez, C.D.P., Schofield, P., Christ, D., Hurley, L.H., et al. (2020). DNA G-Quadruplex and i-Motif Structure Formation Is Interdependent in Human Cells. Journal of the American Chemical Society 142, 20600-20604.

Kobiita, A., Godbersen, S., Araldi, E., Ghoshdastider, U., Schmid, M.W., Spinas, G., Moch, H., and Stoffel, M. (2020). The Diabetes Gene JAZF1 Is Essential for the Homeostatic Control of Ribosome Biogenesis and Function in Metabolic Stress. Cell Rep 32.

Koontz, J.I., Soreng, A.L., Nucci, M., Kuo, F.C., Pauwels, P., van den Berghe, H., Dal Cin, P., Fletcher, J.A., and Sklar, J. (2001). Frequent fusion of the JAZF1 and JJAZ1 genes in endometrial stromal tumors. Proceedings of the National Academy of Sciences of the United States of America 98, 6348-6353. Kshirsagar, R., Khan, K., Joshi, M.V., Hosur, R.V., and Muniyappa, K. (2017). Probing the Potential Role of Non-B DNA Structures at Yeast Meiosis-Specific DNA Double-Strand Breaks. Biophys J 112, 2056-2074. Mergny, J.L., Lacroix, L., Han, X.G., Leroy, J.L., and Helene, C. (1995). Intramolecular Folding of Pyrimidine Oligodeoxynucleotides into an I-DNA Motif. Journal of the American Chemical Society 117, 8887-8898.

Nguyen, T., Fraire, C., and Sheardy, R.D. (2017). Linking pH, Temperature, and K+ Concentration for DNA i-Motif Formation. Journal of Physical Chemistry B 121, 7872-7877. 
Pagano, A., laccarino, N., Abdelhamid, M.A.S., Brancaccio, D., Garzarella, E.U., Di Porzio, A., Novellino, E., Waller, Z.A.E., Pagano, B., Amato, J., et al. (2018). Common G-Quadruplex Binding Agents Found to Interact With i-Motif-Forming DNA: Unexpected Multi-Target-Directed Compounds. Front Chem 6, 281. Peltonen, K., Colis, L., Liu, H., Jaamaa, S., Moore, H.M., Enback, J., Laakkonen, P., Vaahtokari, A., Jones, R.J., af Hallstrom, T.M., et al. (2010). Identification of Novel p53 Pathway Activating Small-Molecule Compounds Reveals Unexpected Similarities with Known Therapeutic Agents. PloS one 5.

Rajendran, A., Nakano, S., and Sugimoto, N. (2010). Molecular crowding of the cosolutes induces an intramolecular i-motif structure of triplet repeat DNA oligomers at neutral pH. Chem Commun 46, 12991301.

Read, M., Harrison, R.J., Romagnoli, B., Tanious, F.A., Gowan, S.H., Reszka, A.P., Wilson, W.D., Kelland, L.R., and Neidle, S. (2001). Structure-based design of selective and potent G quadruplex-mediated telomerase inhibitors. Proceedings of the National Academy of Sciences of the United States of America 98, 4844-4849.

Richard, A.J., Liu, C.C., Klinger, A.L., Todd, M.J., Mezzasalma, T.M., and LiCata, V.J. (2006). Thermal stability landscape for Klenow DNA polymerase as a function of $\mathrm{pH}$ and salt concentration. Bba-Proteins Proteom 1764, 1546-1552.

Rodriguez, R., Muller, S., Yeoman, J.A., Trentesaux, C., Riou, J.F., and Balasubramanian, S. (2008). A Novel Small Molecule That Alters Shelterin Integrity and Triggers a DNA-Damage Response at Telomeres. Journal of the American Chemical Society 130, 15758-+.

Sutherland, C., Cui, Y., Mao, H., and Hurley, L.H. (2016). A Mechanosensor Mechanism Controls the GQuadruplex/i-Motif Molecular Switch in the MYC Promoter NHE III1. Journal of the American Chemical Society.

Takahashi, S., Brazier, J.A., and Sugimoto, N. (2017). Topological impact of noncanonical DNA structures on Klenow fragment of DNA polymerase. Proceedings of the National Academy of Sciences of the United States of America 114, 9605-9610.

Thomas, G., Jacobs, K.B., Yeager, M., Kraft, P., Wacholder, S., Orr, N., Yu, K., Chatterjee, N., Welch, R., Hutchinson, A., et al. (2008). Multiple loci identified in a genome-wide association study of prostate cancer. Nat Genet 40, 310-315.

Wazir, U., Sanders, A.J., Wazir, A., Baig, R.M., Jiang, W.G., Ster, I.C., Sharma, A.K., and Mokbel, K. (2015). Effect of the knockdown of death-associated protein 1 expression on cell adhesion, growth and migration in breast cancer cells. Oncol Rep 33, 1450-1458.

Wright, E.P., Huppert, J.L., and Waller, Z.A.E. (2017). Identification of multiple genomic DNA sequences which form i-motif structures at neutral $\mathrm{pH}$. Nucleic acids research 45, 2951-2959.

Xu, H., Di Antonio, M., McKinney, S., Mathew, V., Ho, B., O'Neil, N.J., Santos, N.D., Silvester, J., Wei, V., Garcia, J., et al. (2017). CX-5461 is a DNA G-quadruplex stabilizer with selective lethality in BRCA1/2 deficient tumours. Nature communications 8, 14432.

Zeraati, M., Langley, D.B., Schofield, P., Moye, A.L., Rouet, R., Hughes, W.E., Bryan, T.M., Dinger, M.E., and Christ, D. (2018). I-motif DNA structures are formed in the nuclei of human cells. Nature Chemistry 10, 631-637. 


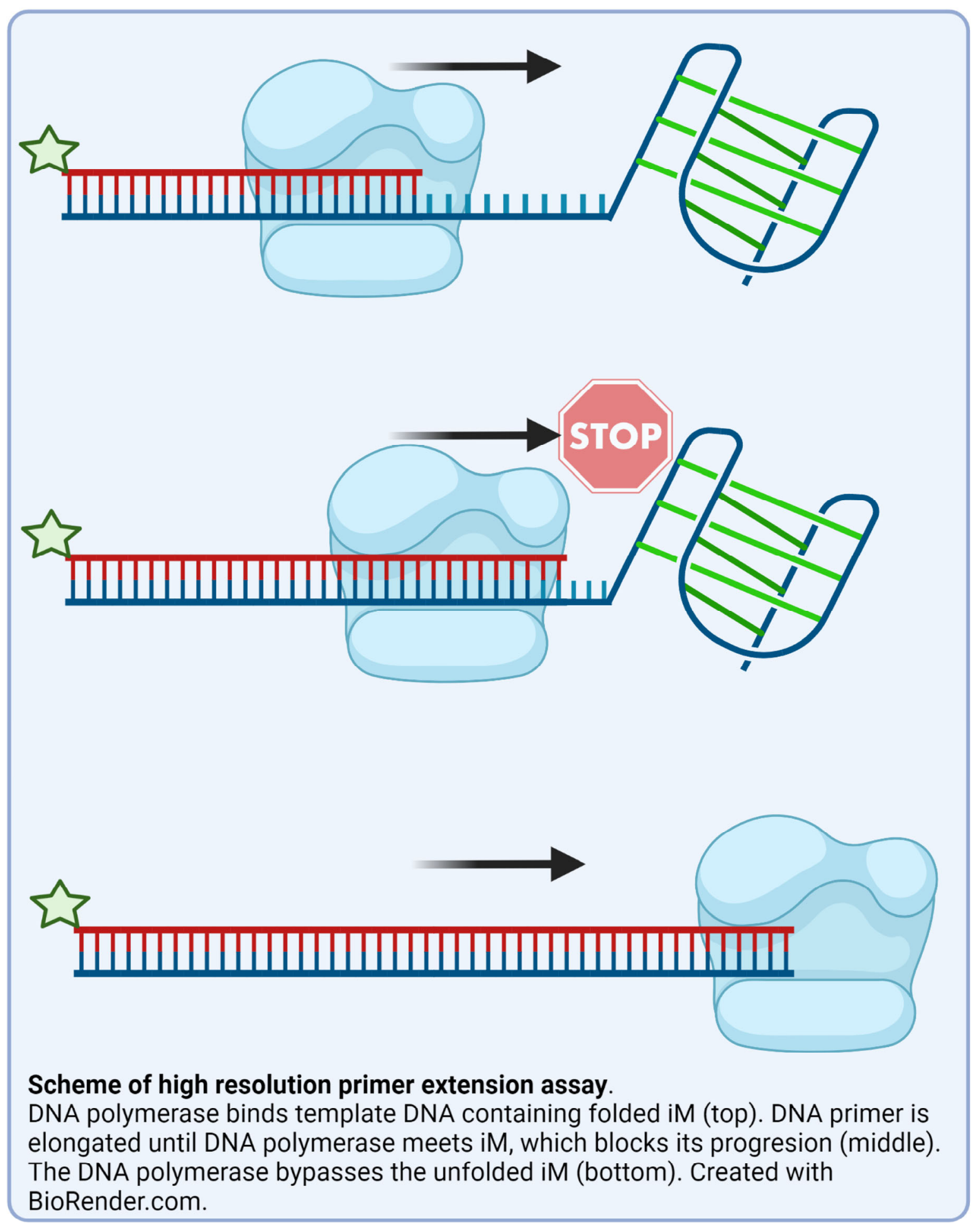



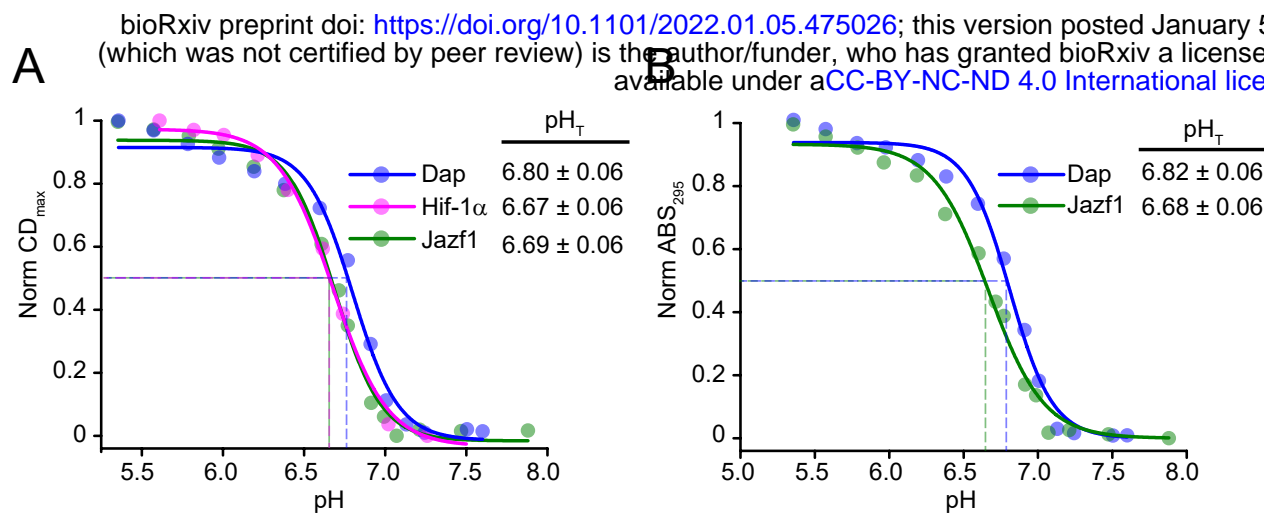

D

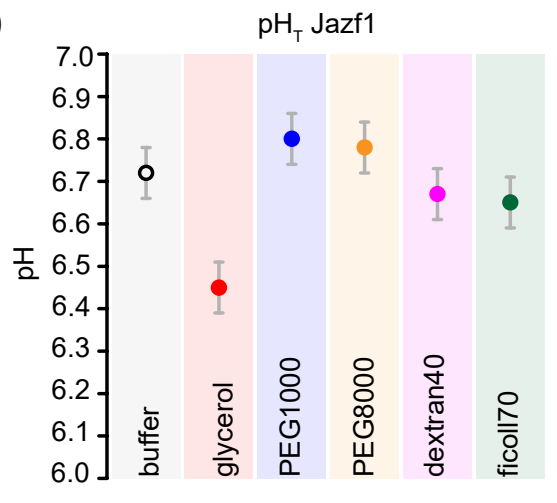

$\mathrm{E}$

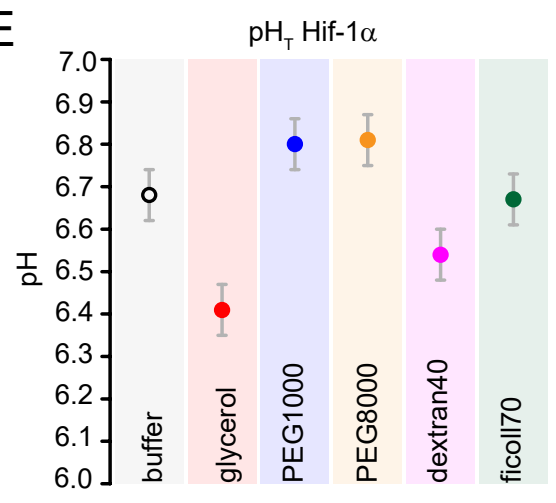

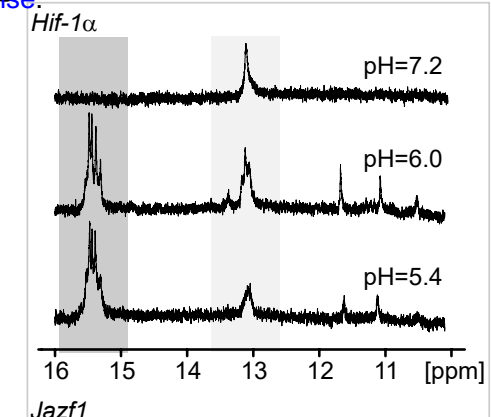
Jazf1
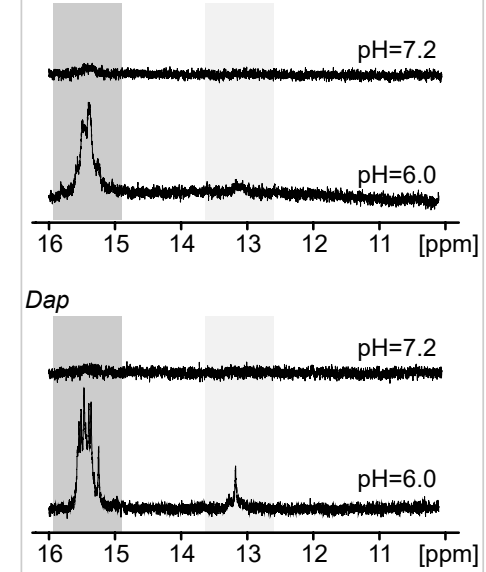

Figure 1. IMs fold at close-to-neutral pH at $25^{\circ} \mathrm{C}$. Fitting curves of $\mathrm{CDmax}(\mathrm{A})$ and $\mathrm{ABS} 295(\mathrm{~B})$ of $\mathrm{iMs}$ spectra recorded at $25{ }^{\circ} \mathrm{C}$. Dotted lines in $\mathrm{A}$ and $\mathrm{B}$ show a $\mathrm{pH}_{\mathrm{T}}$ transition point for each curve. (C) Identification of structural species formed within DNA used in the study. Imino proton region of the 1D ${ }^{1} \mathrm{H}$ NMR spectra of free DNA in Hif1 $\alpha$ (top panel), Jazf1 (middle panel) and Dap (low panel) sequences, $\mathrm{pH}$ of each sample is depicted above each spectrum, spectra were recorded at $25^{\circ} \mathrm{C}$, concentration of DNA was $170 \mu \mathrm{M}$. Dark grey panel shows region for $\mathrm{iM}$, light grey panel show region for Watson-Crick base pairing. Graphical representation of $\mathrm{pH}_{\mathrm{T}}$ values of Jazf1 (D) and Hif-1 $\alpha(E)$ iMs in crowding conditions calculated from $C D_{\max }$ values. Original spectra for $A, B, D$ and $E$ can be found in Figure $S 1$. 
A

bioRxiv preprint doi: https://doi.org/10.1101/2022.01.05.475026; this version posted January 5, 2022. The copyright holder for this preprint (which was not certified by peer review) is the author/funder, who has granted bioRxiv a license to display the preprint in perpetuity. It is made Jazf1 template with primer: available under aCC-BY-NC-ND 4.0 International license.

5' CCCCCCCCGCCCCCGCCCCCGCCCTCCCCC ${ }^{*}{ }^{*}$ atatatatatCGGACGCTCGACGCCATTAATAATGTTTTCA 3'

$5 \frac{1}{4} \frac{}{2} \frac{1}{1} \quad$ 3' GCCTGCGAGCTGCGGTAATTATTACAAAAGT 5'

B
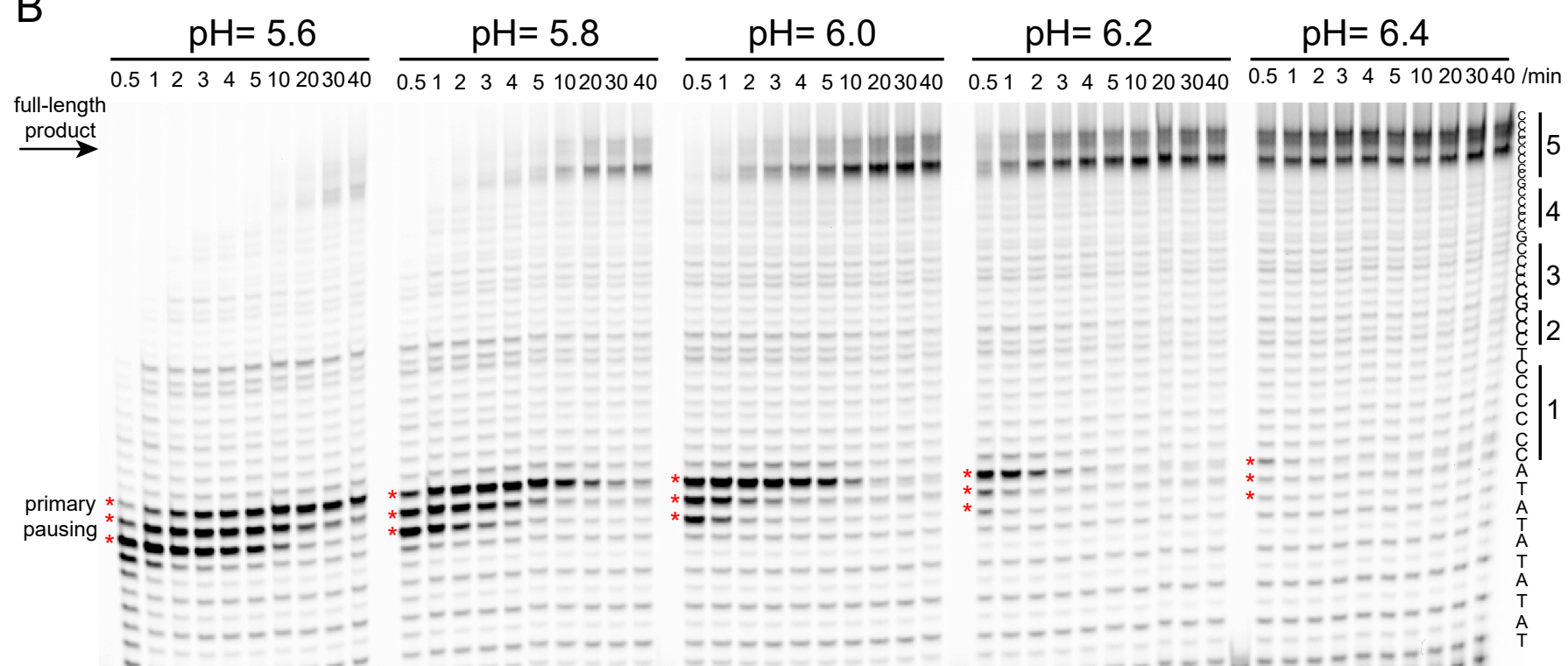

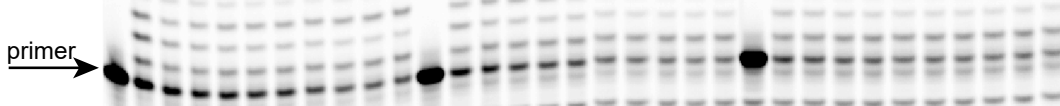

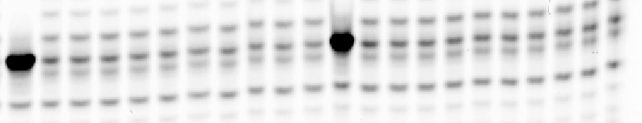

C

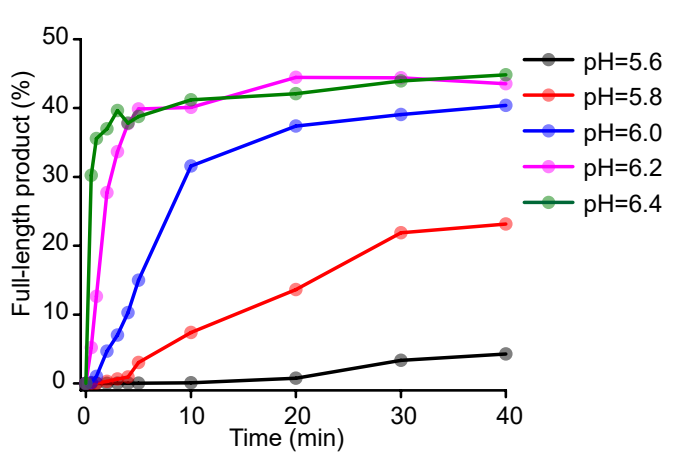

$\mathrm{D}$

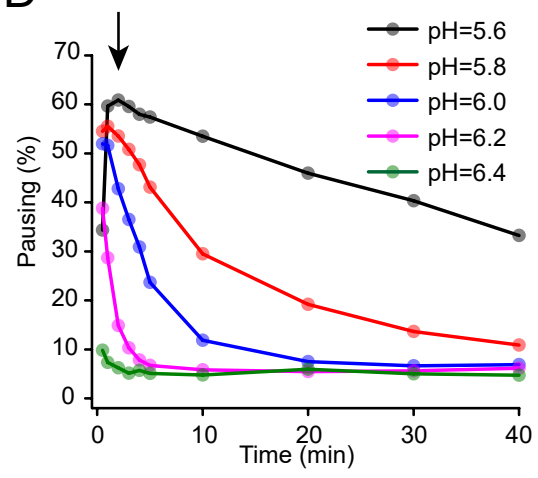

$E$

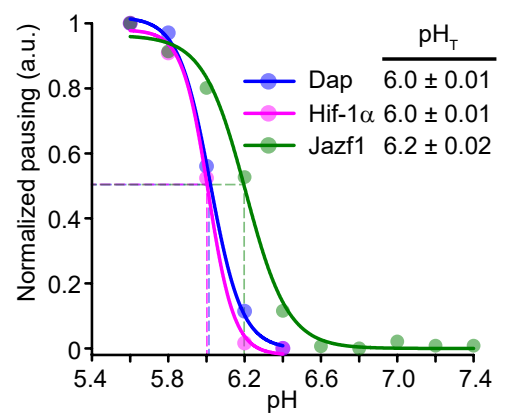

Figure 2. Jazf1 iM pauses DNA synthesis in high resolution primer extension assay. Sequence $(A)$ and representative sequencing gel (B) of primer extension assay with template containing Jazf1 iM sequence, $\mathrm{pH}$ of the reaction is written above each gel. Time-points $(\mathrm{min})$ when individual samples were collected is described above each well. C-tracts from iM sequence are underlined in A and depicted on the right side of the gel. Pausing sites are depicted as red stars $\left(^{* * *}\right)$ in each reaction and shown also in the sequence in A. Quantification of full-length product (C) and pausing signal (D) of each reaction is describing an effect of $\mathrm{pH}$ on overall reaction and $\mathrm{iM}$, respectively. Normalized pausing of primer extension assay with all three iM templates as a function of $\mathrm{pH}(\mathrm{E})$. 
A

J pioRxiv preprint doi: https://doi.org/10.1101/2022.01.05.475026; this version posted January 5, 2022. The copyright holder for this preprint JazfWhlemala available under $\mathrm{a}_{\mathrm{C}} \mathrm{C}_{\mathrm{F}} \mathrm{BY}$-NC-ND 4.0 International license.

5' CCCCCCCCGCCCCCGCCCCCGCCCTCCCCCCatatatatatCGGACGCTCGACGCCATTAATAATGTTTTCA 3'

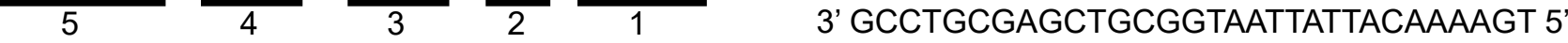
B
$\frac{\text { buffer }}{0.51234510203040} \frac{\text { glycerol }}{0.51234510203040} \frac{\text { PEG1000 }}{0.51234510203040} \frac{\text { dextran40 }}{0.512345102030}$

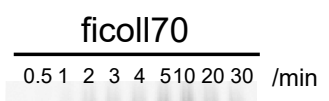

$\stackrel{\text { Full produc }}{\longrightarrow}$
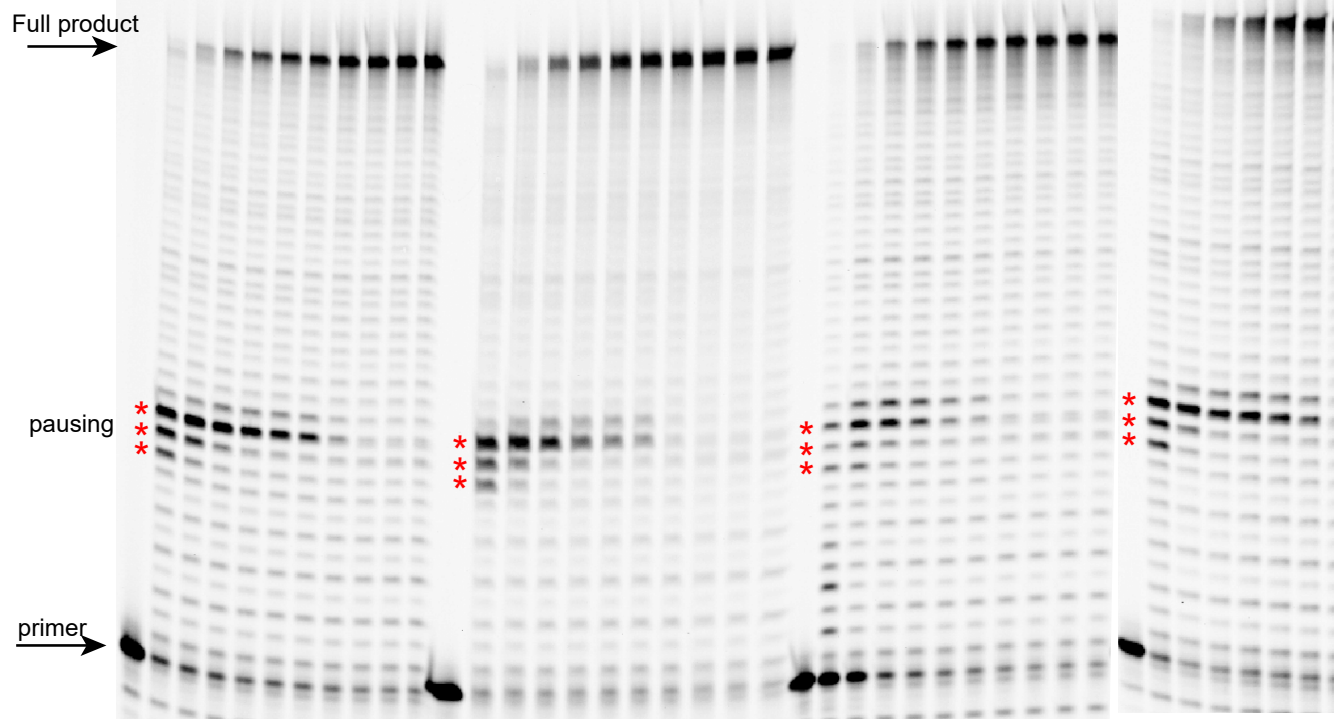

C

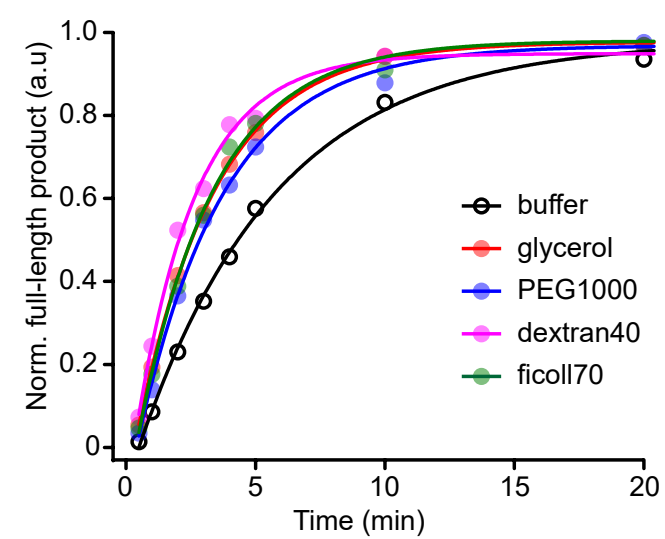

$E$

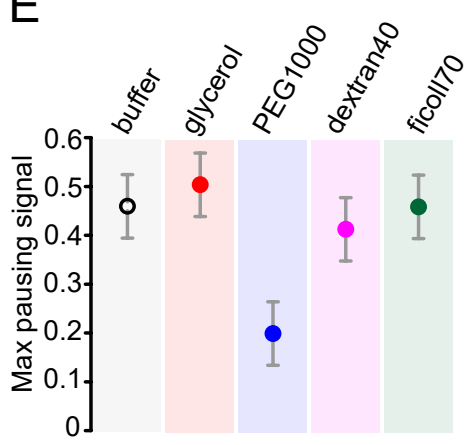

$\mathrm{F}$
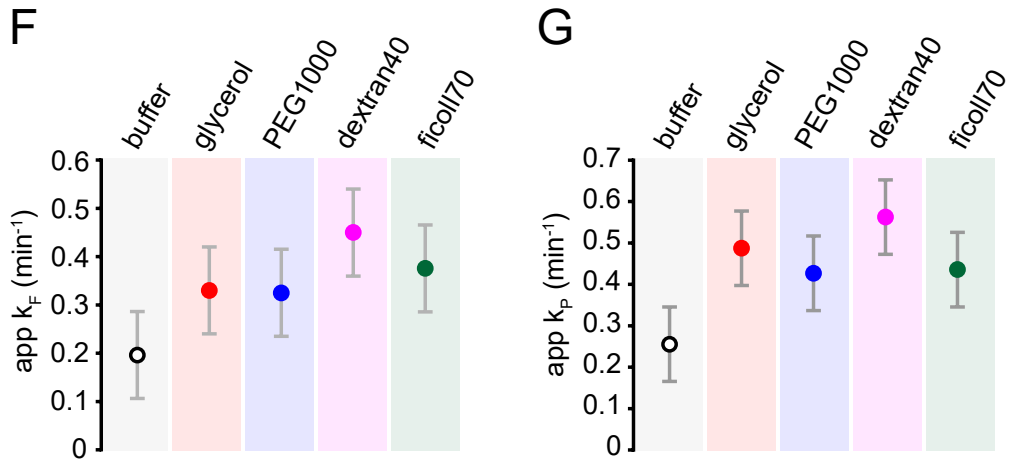

Figure 3. Molecular crowders and co-solutes do not increase the stability of Jazf1 iM structure in high-resolution primer extension assay, but facilitate the reaction. Sequence $(A)$ and representative sequencing gel $(B)$ of primer extension assay with template containing Jazf1 iM sequence. Reactions were supplemented with co-solutes or molecular crowders, specified above each reaction. Time of sample collection ( $\mathrm{min}$ ) is written above each well. C-tracts from iM sequence are underlined in A and depicted on the right side of the gel. Pausing sites are depicted as red stars $\left(^{* * *}\right)$ in each reaction and are also marked in A. Quantified full-length products of all reactions were normalized to the maximum signal (C). Pausing signals of individual reactions were subtracted by their minimal signal (D). Proportion of maximum pausing signal for each condition was compared $(E)$. Data from individual reactions were fitted into exponential equation of the first order in OriginLab software and apparent rate constants for synthesis of full-length product $k_{F}(F)$ and rate for disappearance of pausing site $k_{P}(G)$ were calculated and. All data are shown as mean \pm pooled SD. 


\section{A}

Jazf1 5' (which was not certified by peer review) is the author/funder, "who has granted biokxiv a license to display the preprint in perpetuity. It is made 3

$5 \frac{1}{3} \frac{3}{2} \frac{3}{1} \quad$ 3' GCCTGCGAGCTGCGGTAATTATTACAAAAGT 5'

Hif- $1 \alpha$ template with primer:

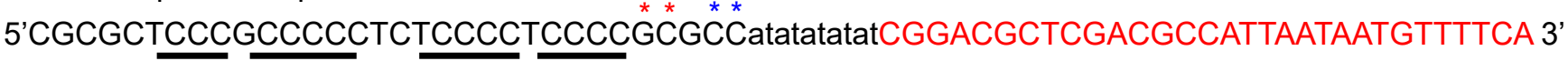
$4 \frac{1}{3} \frac{C}{1}$ 3' GCCTGCGAGCTGCGGTAATTATTACAAAAGT 5'

non-iM template with primer:

5' GAGACCATTCAAAAGGATAATGTTTGTCATTatatatatatCGGACGCTCGACGCCATTAATAATGTTTTCA 3' 3' GCCTGCGAGCTGCGGTAATTATTACAAAAGT 5'

B

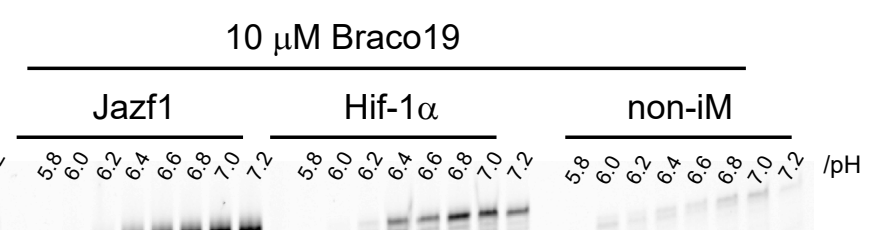
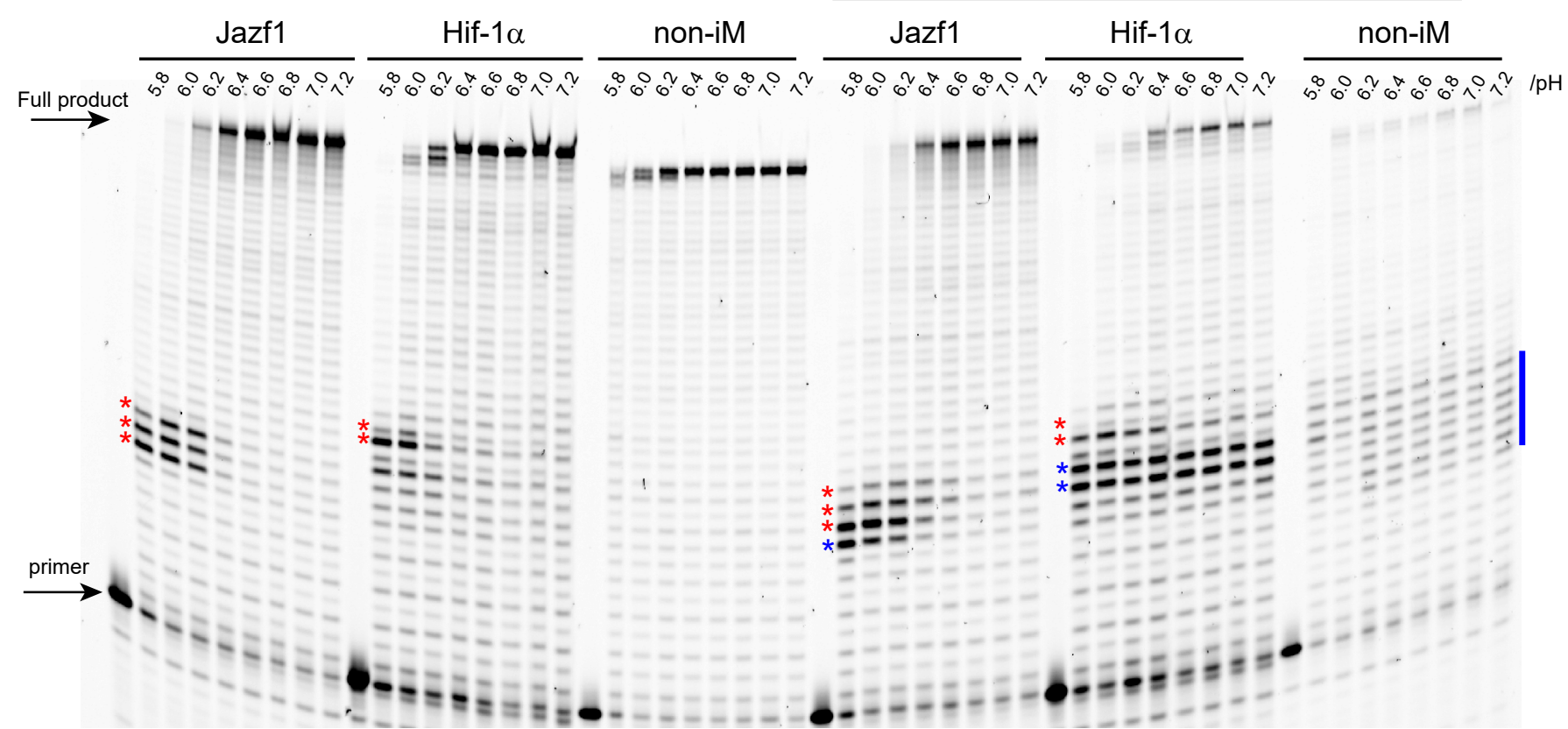
$10 \mu \mathrm{M}$ CX-5461
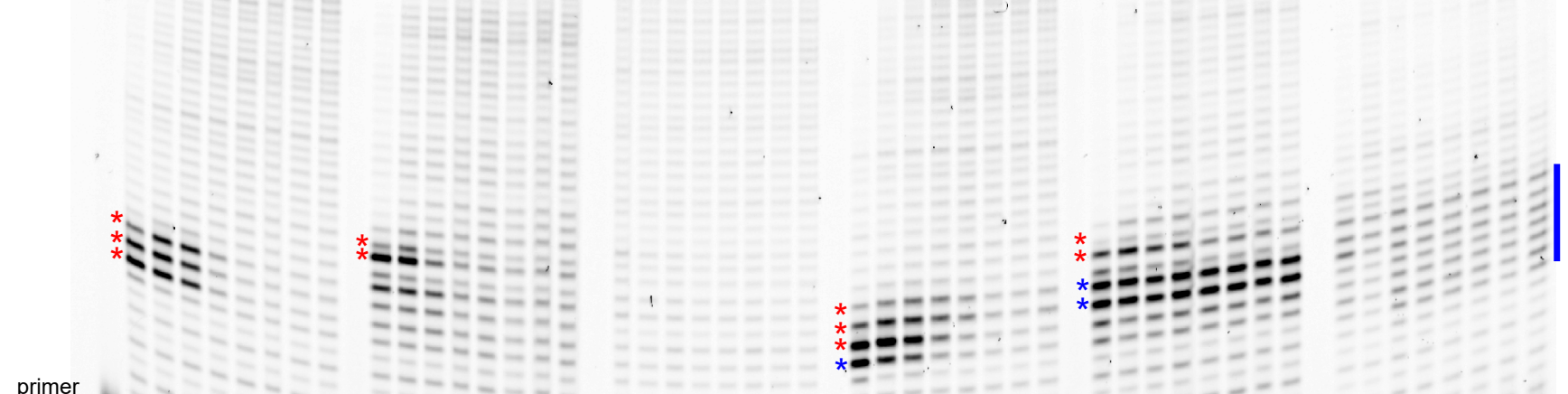

C

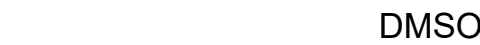

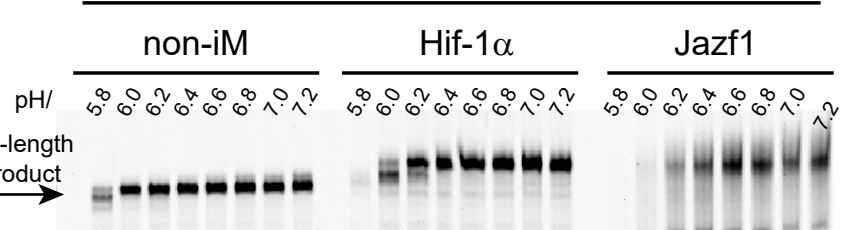
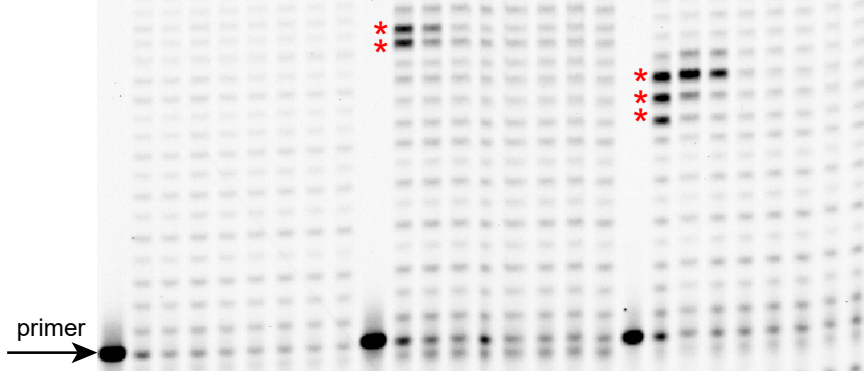

E
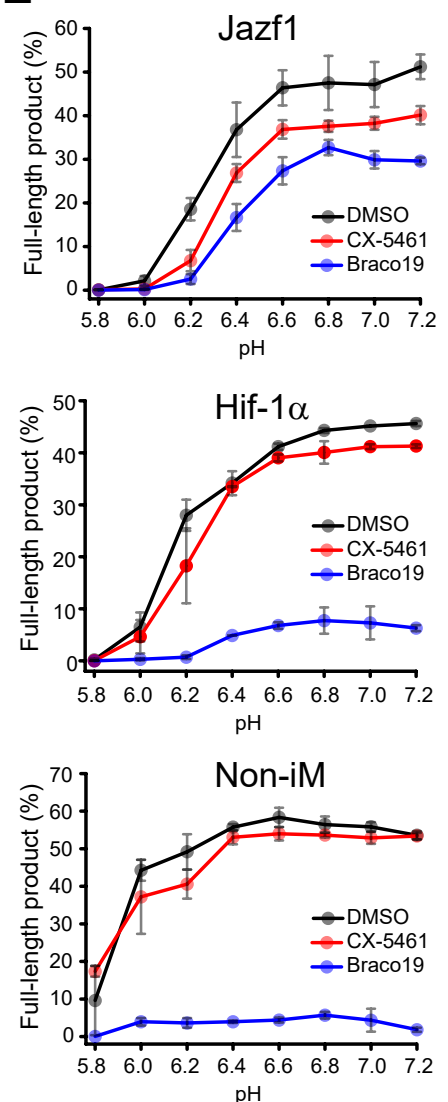
Figure 4. CX-5461 specifically stabilizes iMs in high resolution primer extension assay.

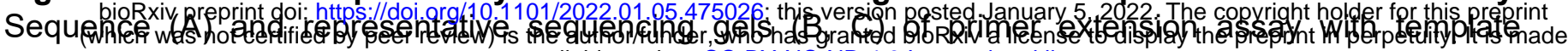

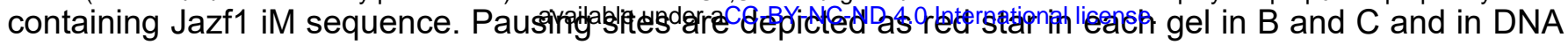
sequence in A. Additional pausing sites formed upon binding of Braco19 are depicted as blue star in the gels and in DNA sequence in A. Blue line in non-iM DNA sequence in A and gel in B shows polymerase pausing caused by Braco19. IM containing template is written above each gel set and $\mathrm{pH}$ of each reaction is depicted above each well in B and C. Quantification of pausing signal (D) represents the sum of the signal depicted by red stars for DMSO and CX-5461 reaction and blue stars in case of Braco19 treatment. Quantification of full-length product (E) for all three DNA templates. 
A

bioRxiv preprint doi: https://doi.org/10.11 $/ 2022.01 .05 .475026$; this version posted Janualy 5, 2022. The copyright holder for this preprint (which was not certified by peer review) is the author/funder, who has granted bioRxiv a license to display the preprint in perpetuity. It is made
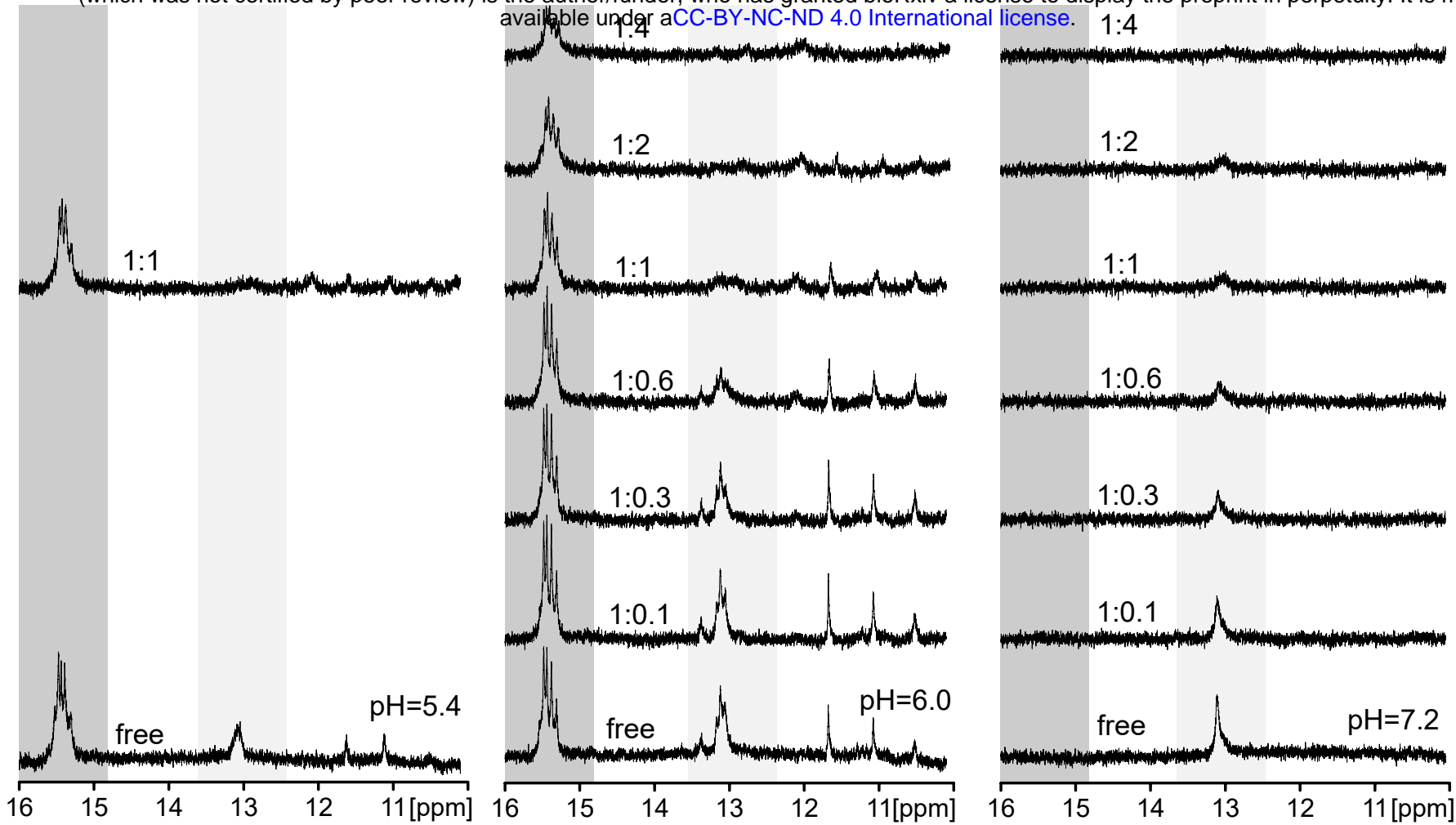

Figure 5. Braco19 interacts with both non-iM and iM structures folded within the Hif-1 $\alpha$ DNA region. Imino proton regions of the 1D ${ }^{1} \mathrm{H}$ NMR spectra of $\mathrm{Hif}-1 \alpha$ DNA in $\mathrm{pH}=5.4(\mathrm{~A}), \mathrm{pH}=6.0(\mathrm{~B})$ and $\mathrm{pH}=7.2(\mathrm{C})$ titrated with Braco19. Spectra were recorded at $25^{\circ} \mathrm{C}$. Concentration of DNA was $170 \mu \mathrm{M}$. Ratio of DNA:Braco19 is indicated above each spectrum. Dark grey panel shows region for iM, light grey panel shows region for Hairpin structure. 
bioRxiv preprint doi: https://doi.org/10.1101/2022.01.05.475026; this version posted January 5, 2022. The copyright holder for this preprint

(which was not certified by peer review) is the author/funder, who has granted bioRxiv a license to display the preprint in perpetuity. It is made available under aCC-BY-NC-ND 4.0 International license.

Insights into I-motif stabilization by high resolution primer extension assays: Its

strengths and limitations

Jan Jamroskovic ${ }^{1 \#}$, Marco Deiana ${ }^{1}$, and Nasim Sabouri. ${ }^{1 \#}$

${ }^{1}$ Department of Medical Biochemistry and Biophysics, Umeå University, 90187 Umeå, Sweden

\# Co-corresponding authors

\section{Supplementary information}


bioRxiv preprint doi: https://doi.org/10.1101/2022.01.05.475026; this version posted January 5,2022 . The copyright holder for this preprint (which was not certified by peer review) is the author/funder, who has granted bioRxiv a license to display the preprint in perpetuity. It is made available under aCC-BY-NC-ND 4.0 International license.

Table S1. Oligonucleotides used in the study

\begin{tabular}{|l|l|l|}
\hline DNA oligo & Sequence $5^{\prime} \rightarrow 3^{\prime}$ direction & Study \\
\hline Jazf1 & CCCCCCCCGCCCCGCCCCCGCCCTCCCCCC & $\begin{array}{l}\text { (Wright et } \\
\text { al., 2017) }\end{array}$ \\
\hline Dap & CCCCCGCCCCCGCCCCCGCCCCCGCCCCC & $\begin{array}{l}\text { (Wright et } \\
\text { al., 2017) }\end{array}$ \\
\hline Hif1- $\alpha$ & CGCGCTCCCGCCCCCTCTCCCCTCCCCGCGCC & $\begin{array}{l}\text { (Takahashi } \\
\text { et al., 2017) }\end{array}$ \\
\hline $\begin{array}{l}\text { Tet-primer } \\
\text { Jazf1- } \\
\text { template }\end{array}$ & TCAAAACATTATTAATGGCGTCGAGCGTCCG & $\begin{array}{l}\text { (Deiana et } \\
\text { al., 2020) }\end{array}$ \\
\hline $\begin{array}{l}\text { Dap- } \\
\text { template }\end{array}$ & CCCCCGCCCCCGCCCCCGCCCCCGCCCCCatatatatatCGGACGCTCGACGCCATTAATAATGTTTTCA & This study \\
\hline $\begin{array}{l}\text { Hif1- } \alpha- \\
\text { template }\end{array}$ & CGCGCTCCCGCCCCCTCTCCCCTCCCCGCGCCatatatatatCGGACGCTCGACGCCATTAATAATGTTTTCA study & This study \\
\hline $\begin{array}{l}\text { Non-I-motif- } \\
\text { template }\end{array}$ & GAGACCATTCAAAAGGATAATGTTTGTCATTatatatatatCGGACGCTCGACGCCATTAATAATGTTTTCA & This study \\
\hline
\end{tabular}


biARxiv preprint doi: https://doi.org/10.1101/2022.01.05.475026; this ver夰n posted January 5, 2022. The copyright holder for this preprint (which was not certified loypeer review) is the author/funder, who has granted bioRxiv a license to display the preprint in perpetuity. It is made

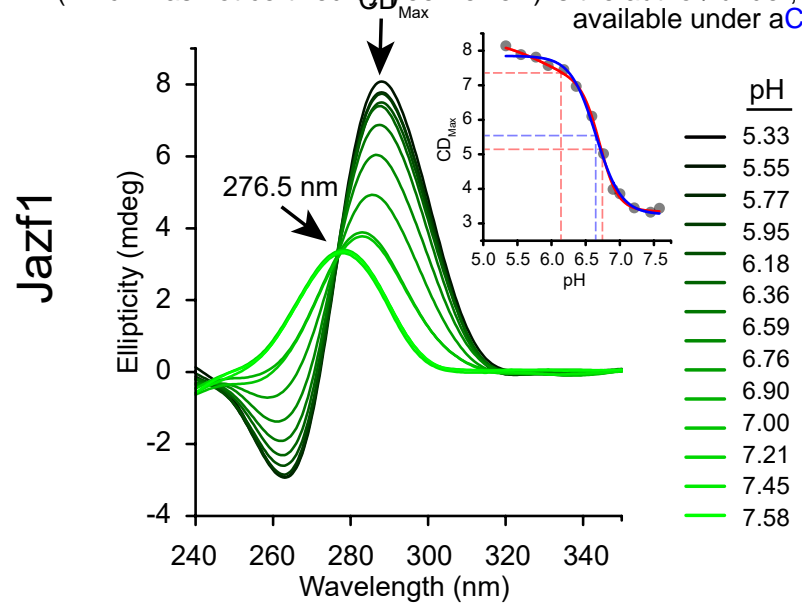

C
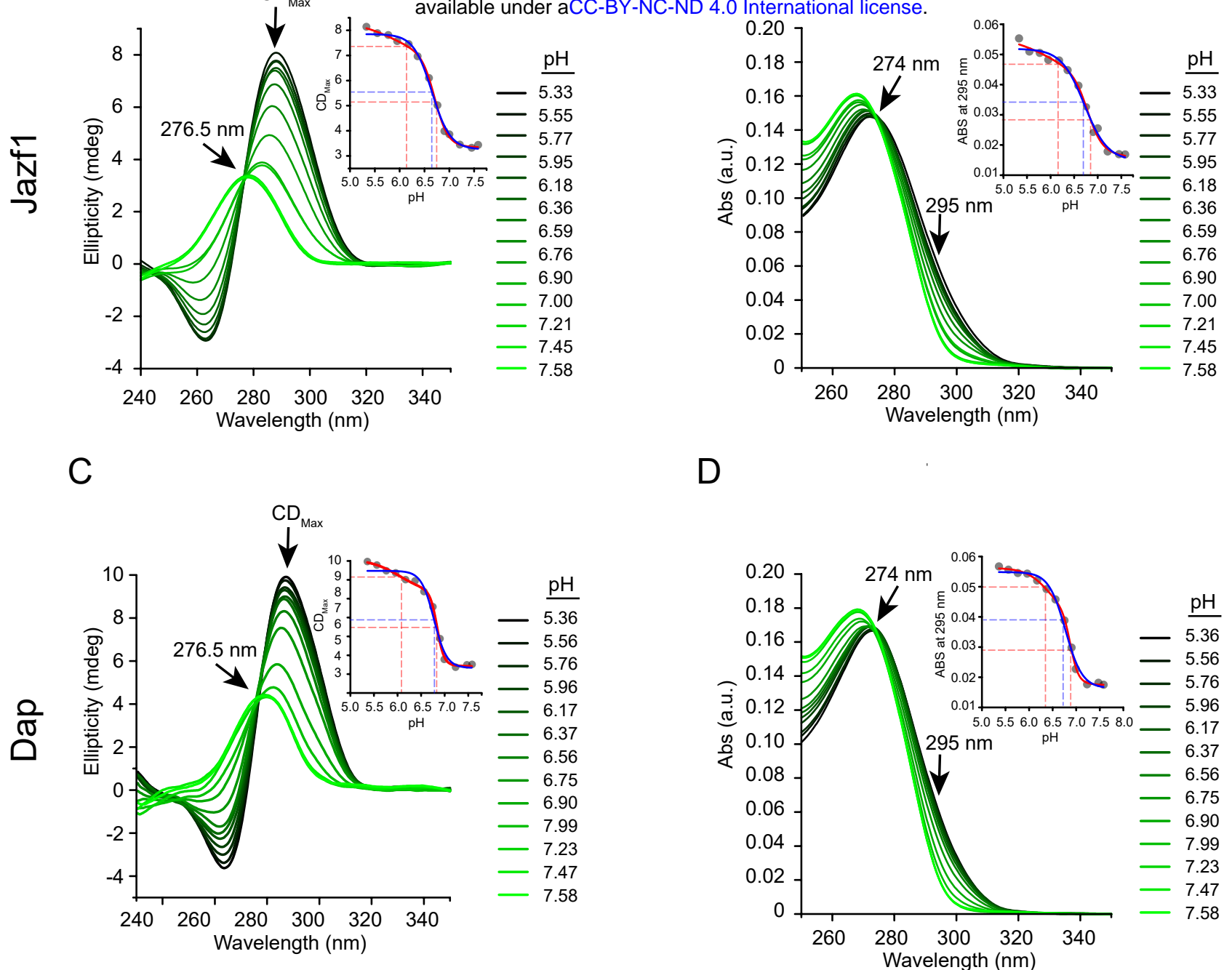

D

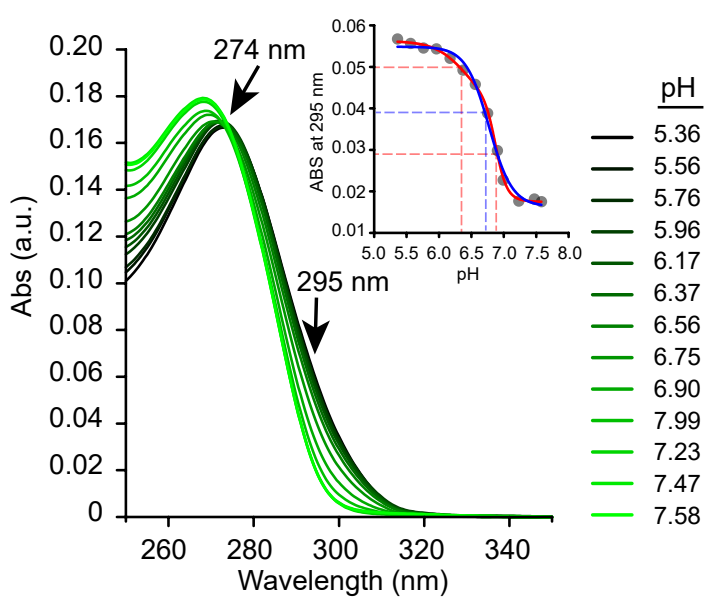

$\mathrm{E}$

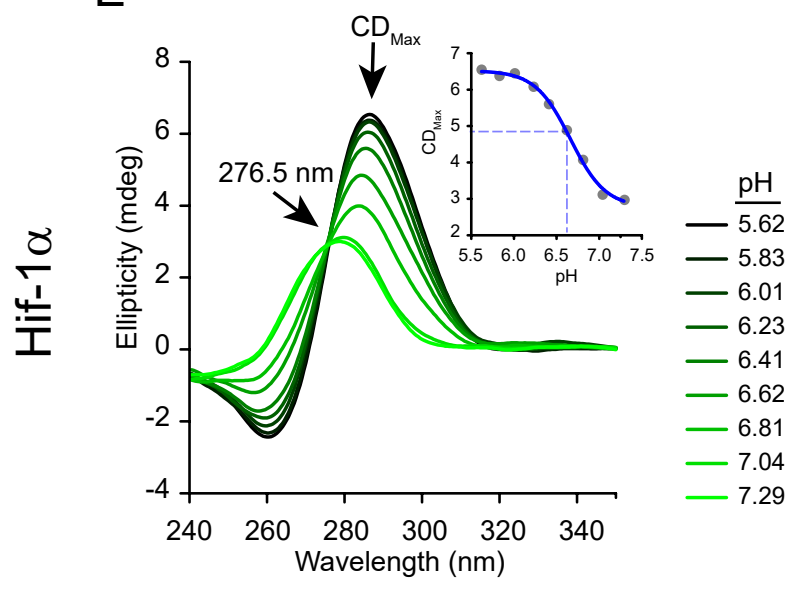

Figure S1. IMs fold at close-to-neutral $\mathrm{pH}$ at $25^{\circ} \mathrm{C} . \mathrm{CD}$ and absorption spectra of iMs recorded at various $\mathrm{pH}$ : $\mathrm{CD}(\mathrm{A})$ and absorption $(\mathrm{B})$ spectra of Jazf1, $\mathrm{CD}(\mathrm{C})$ and absorption (D) spectra of Dap, CD spectra of Hif-1 $\alpha(E)$. Upper right corner of each graph contains $C_{\max }$ or $A B S_{295}$ values plotted over $\mathrm{pH}$. These data were fitted into dose-response (blue) or bi-dose-response function (red) in OriginLab software for a visual comparison. Presented data are from one representative experiment. Final values are listed in Figure 1 and Figure S2. 
bioRশA preprint doi: https://doi.org/10.1101/2022.01.05.475026; this V Vosion posted January 5, 2022. The copyright holder for this preprint (which was not certified by peer review) is the author/funder, who has granted bioRxiv a license to display the preprint in perpetuity. It is made

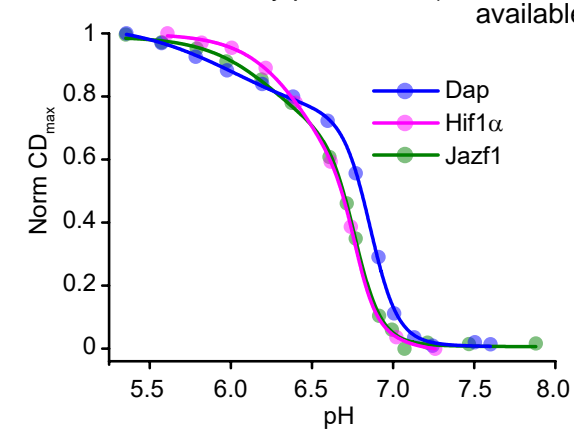

C

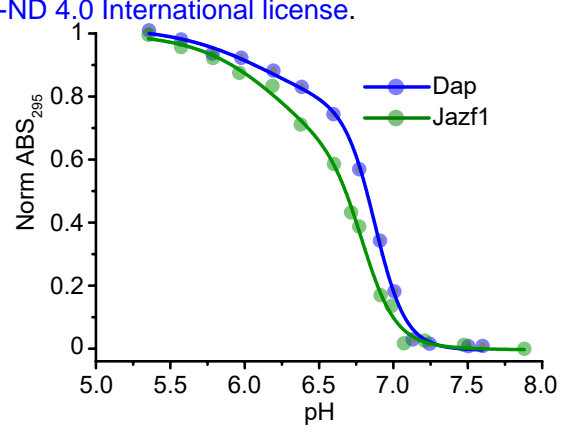

$C D_{\max }$ at $25^{\circ} \mathrm{C}$

$\mathrm{ABS} 295$ at $25^{\circ} \mathrm{C}$

\begin{tabular}{l|cc|cc}
\hline & $\mathbf{p H}_{\mathrm{T} 1}$ & $\mathbf{p H}_{\mathrm{T} 2}$ & $\mathbf{p H}_{\mathbf{T} 1}$ & $\mathbf{p H}_{\mathbf{T}}$ \\
Jazf1 & $6.19 \pm 0.26(4)$ & $6.75 \pm 0.04(4)$ & $6.17 \pm 0.09(3)$ & $6.79 \pm 0.004(3)$ \\
Dap & $6.02 \pm 0.13(3)$ & $6.86 \pm 0.02(3)$ & $6.01 \pm 0.36(3)$ & $6.87 \pm 0.01(3)$ \\
Hif-1a* & $\mathrm{ND}$ & $\mathrm{ND}$ & $\mathrm{ND}$ & $\mathrm{ND}$
\end{tabular}

Figure S2. IMs fold at close-to-neutral pH at $25^{\circ} \mathrm{C} . \mathrm{CD}_{\max }(\mathrm{A})$ and $\mathrm{ABS}_{295}(\mathrm{~B})$ of iMs spectra recorded at $25{ }^{\circ} \mathrm{C}$. Data were fit into bi dose-response function to obtain two $\mathrm{pH}_{\mathrm{T} 1}$ and $\mathrm{pH}_{\mathrm{T} 2}$ values from two slopes. $\mathrm{pH}_{\mathrm{T} 1}$ and $\mathrm{pH}_{\mathrm{T} 2}$ values are listed in table in $\mathrm{C}$. $\mathrm{CD}$ and absorption data were averaged and fitted in OriginLab software for visualization purpose only. ${ }^{*}$ Fitting not successful/data missing. 
A

bioRxiv preprint doi; https://doi.org/10.1101/2022.01.05.475026; this version posted January 5, 2022. The copyright holder for this preprint

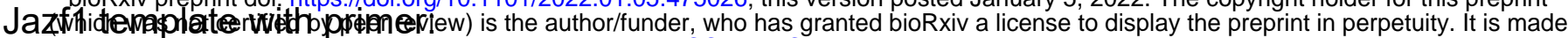
available under aÇC-BY-NC-ND 4.0 International license.

5' CCCCCCCCGCCCCCGCCCCCGCCCTCCCCCCatatatatatCGGACGCTCGACGCCATTAATAATGTTTTCA 3'

$5 \frac{3}{4} \frac{3}{2} \frac{1}{1} \quad$ GCCTGCGAGCTGCGGTAATTATTACAAAAGT 5'

$\mathrm{B}$

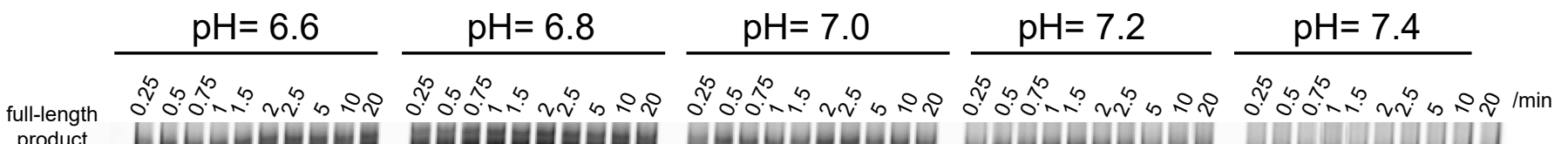

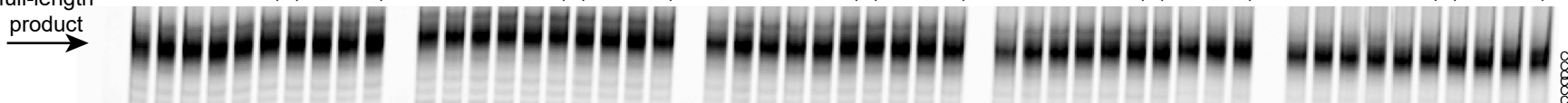

primer

C

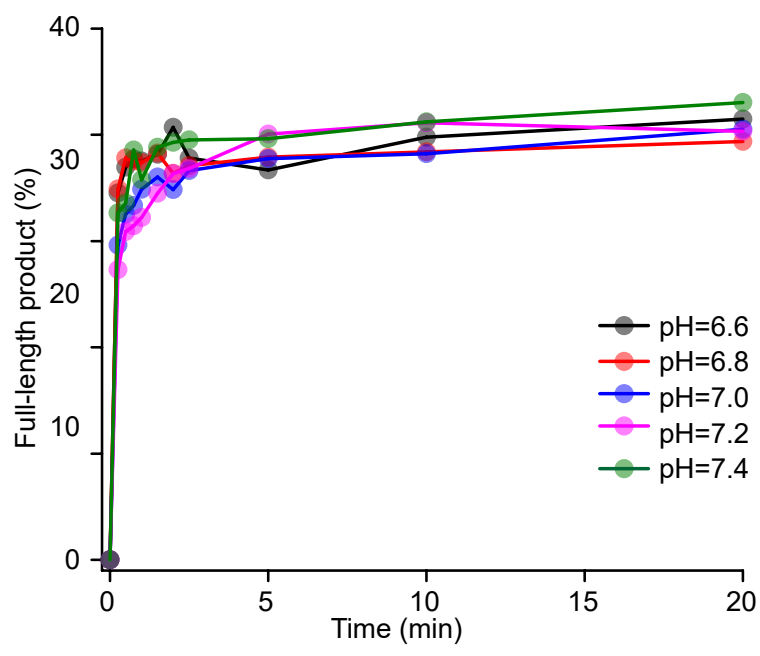

D

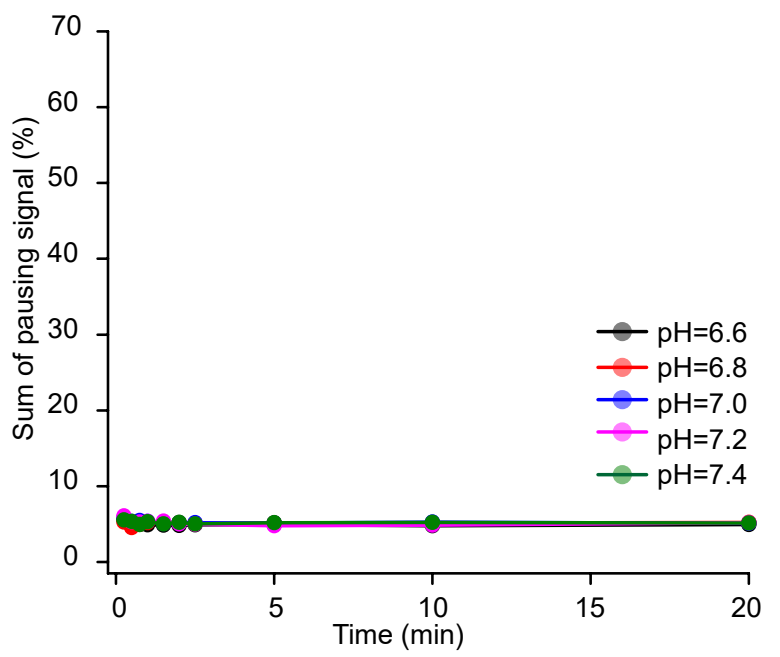

Figure S3. Jazf1 iM does not pause the DNA polymerase above $\mathrm{pH}=6.6$ during DNA synthesis in primer extension assay. Sequence $(A)$ and representative sequencing gel $(B)$ of primer extension assay with template containing Jazf1 $\mathrm{iM}$ sequence, $\mathrm{pH}$ of the reaction is written above each gel. Time-points when individual samples were collected is written above each well. C-tracts from iM sequence are underlined in $A$ and depicted on the right side of the gel. Pausing site is depicted as red stars $\left(^{* * *}\right)$ in each reaction and shown also in A. Quantification of full-length product (C) and pausing signal (D) of each reaction is describing an effect of $\mathrm{pH}$ on overall reaction and $\mathrm{iM}$, respectively. 
A

bioRxiv preprint doi: https://doi.org/10.1101/2022.01.05.475026; this version posted January 5, 2022. The copyright holder for this preprint

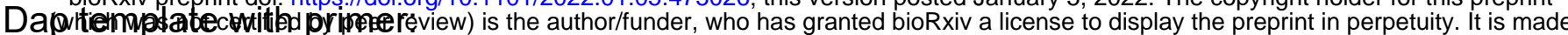
available under aCC-BY-NC-ND 4.0 International license.

\section{5' CCCCCGCCCCCGCCCCCGCCCCCGCCCCCatatatatatCGGACGCTCGACGCCATTAATAATGTTTTCA 3'
3
3' GCCTGCGAGCTGCGGTAATTATTACAAAAGT 5' \\ 5 \\ 4}

B
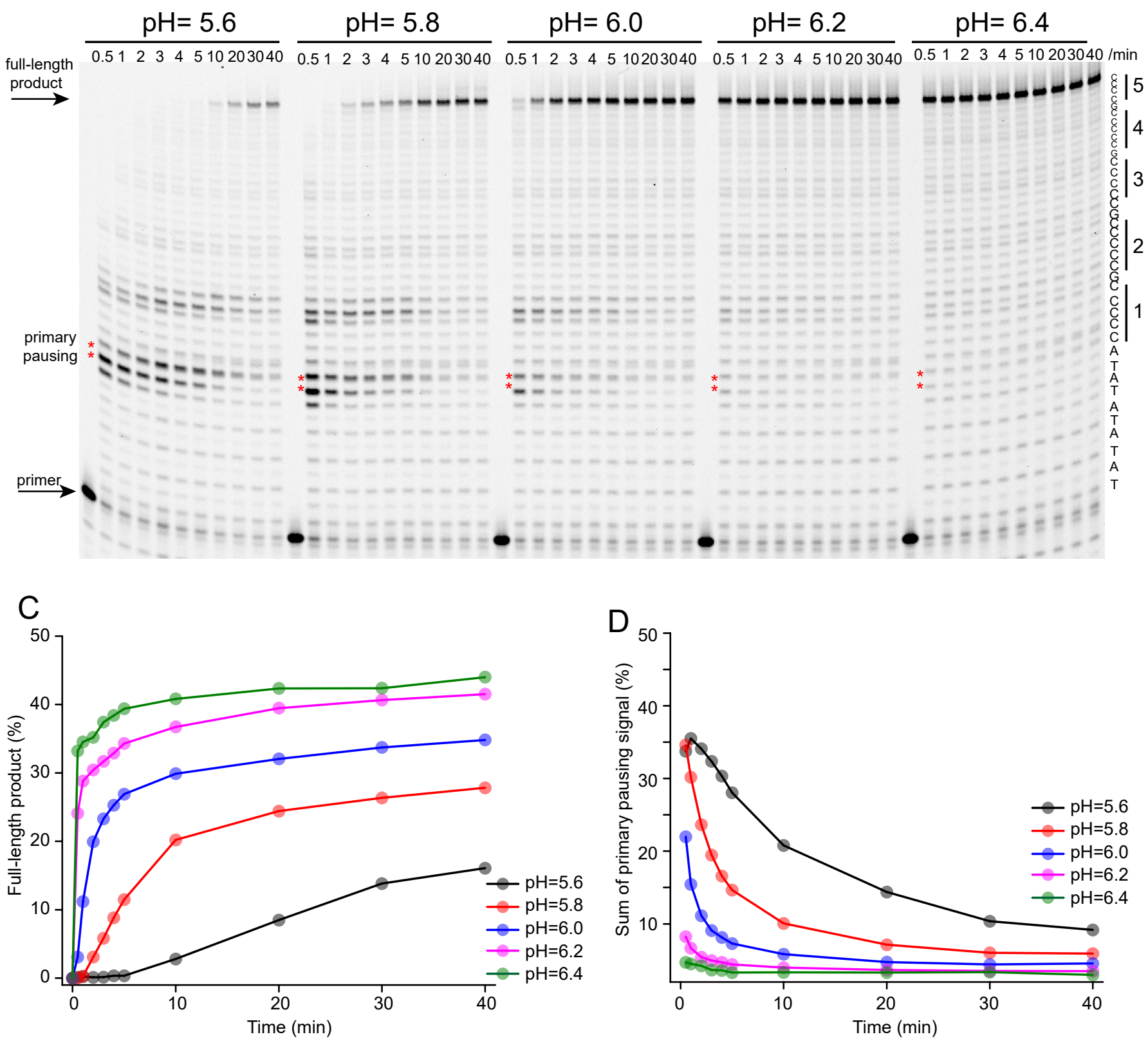

Figure S4. Dap iM pauses DNA synthesis in $\mathrm{pH}=5.6-6.0$. Sequence $(A)$ and representative sequencing gel $(B)$ of primer extension assay with template containing Dap iM sequence, $\mathrm{pH}$ of the reaction is written above each gel. Time-points when individual samples were collected is written above each well. C-tracts from iM sequence are underlined in $\mathrm{A}$ and depicted on the right side of the gel. Main pausing sites are depicted as red stars $\left.{ }^{* *}\right)$ in each reaction and shown also in A. Quantification of fulllength product $(C)$ and the sum of pausing signal (D) of each reaction is describing an effect of $\mathrm{pH}$ on overall reaction and $\mathrm{iM}$, respectively. 
A

bioRxiv preprint doi: https://doi.org/10.1101/2022.01.05.475026; this version posted January 5, 2022. The copyright holder for this preprint

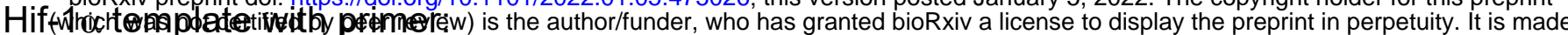
available under aCC-BY-NC-ND 4.0 International license.

5'CGCGCTCCCGCCCCCTCTCCCCTCCCC ${ }^{*}$ CैGCCatatatatatCGGACGCTCGACGCCATTAATAATGTTTTCA 3'
$4 \frac{3}{3}$
1
3' GCCTGCGAGCTGCGGTAATTATTACAAAAGT 5'

B

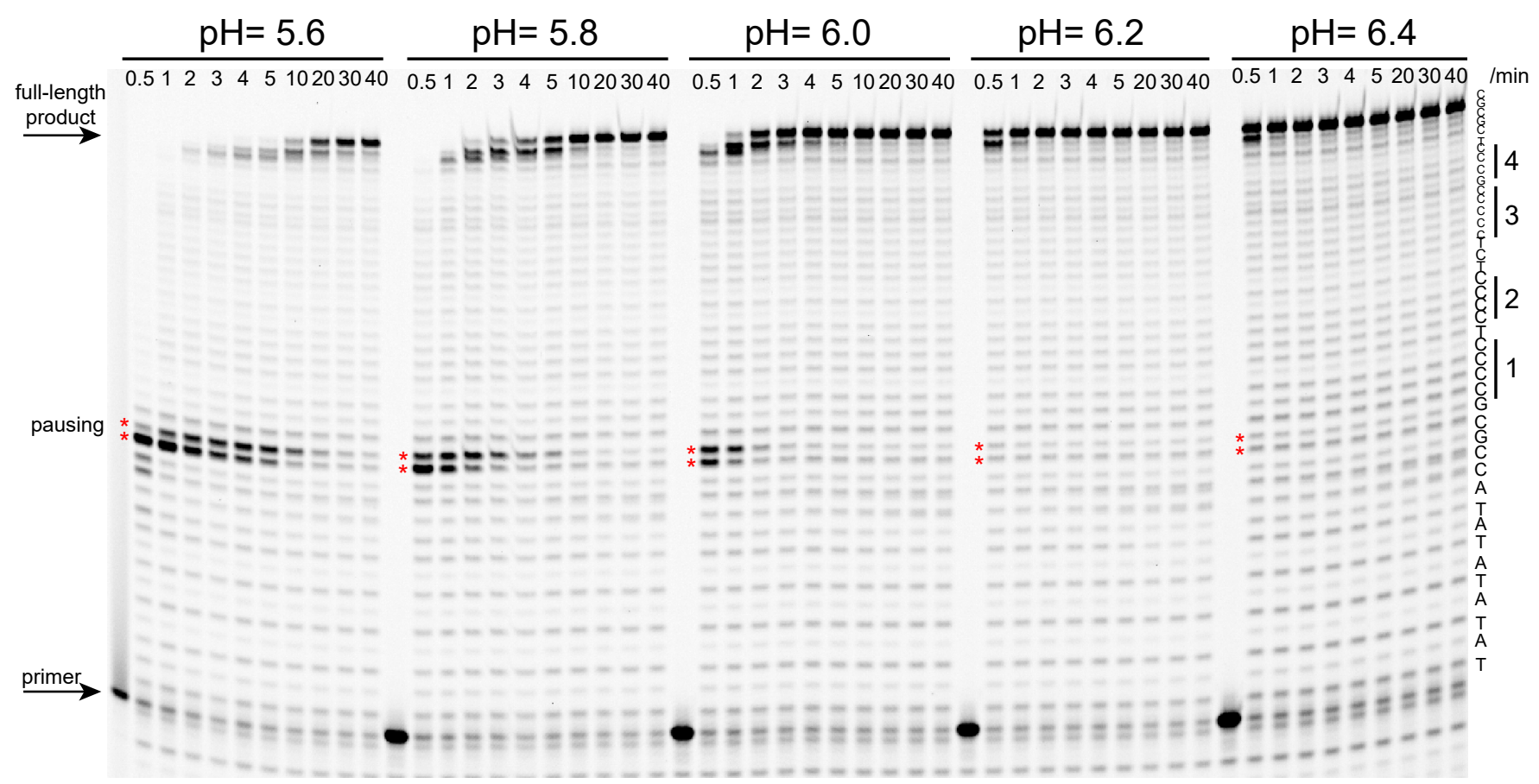

C
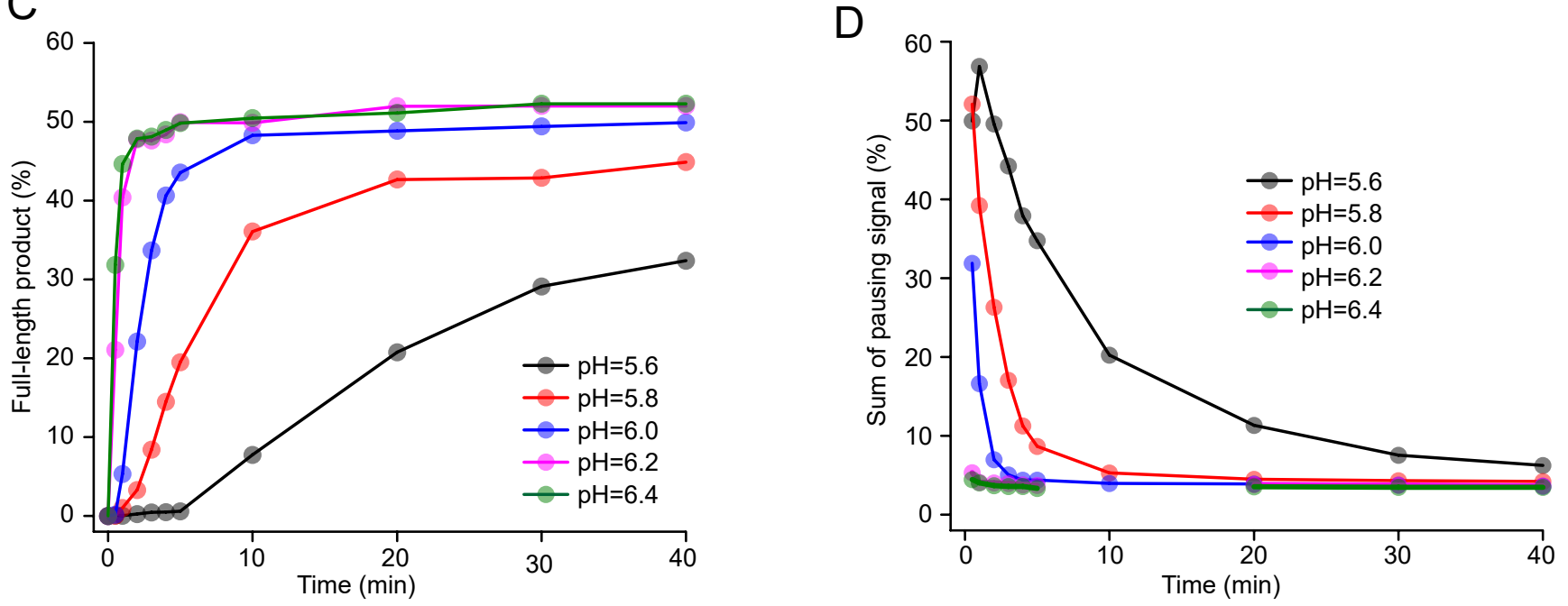

Figure S5. Hif-1 $\alpha$ iM pauses DNA synthesis in $\mathrm{pH}=5.6-6.0$. Sequence $(A)$ and representative sequencing gel $(B)$ of primer extension assay with template containing Hif- $1 \alpha$ iM sequence. $\mathrm{pH}$ of the reaction is written above each gel. Time-points when individual samples were collected is written above each well. C-tracts from iM sequence are underlined in $\mathrm{A}$ and depicted on the right side of the gel. Pausing site is depicted as red stars $\left({ }^{* *}\right)$ in each reaction and shown also in A. Quantification of fulllength product $(C)$ and the sum of pausing signal $(D)$ of each reaction is describing an effect of $\mathrm{pH}$ on overall reaction and $\mathrm{iM}$, respectively. 
A

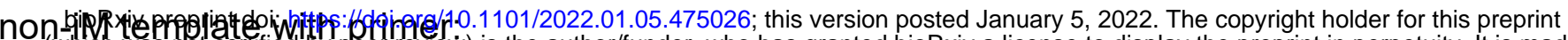
(which was not certified by peer review) is the author/funder, who has granted bioRxiv a license to display the preprint in perpetuity. It is made

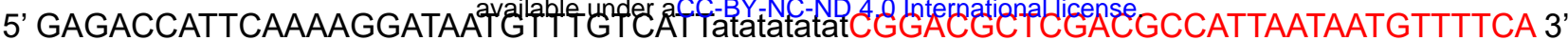

3' GCCTGCGAGCTGCGGTAATTATTACAAAAGT 5'

B

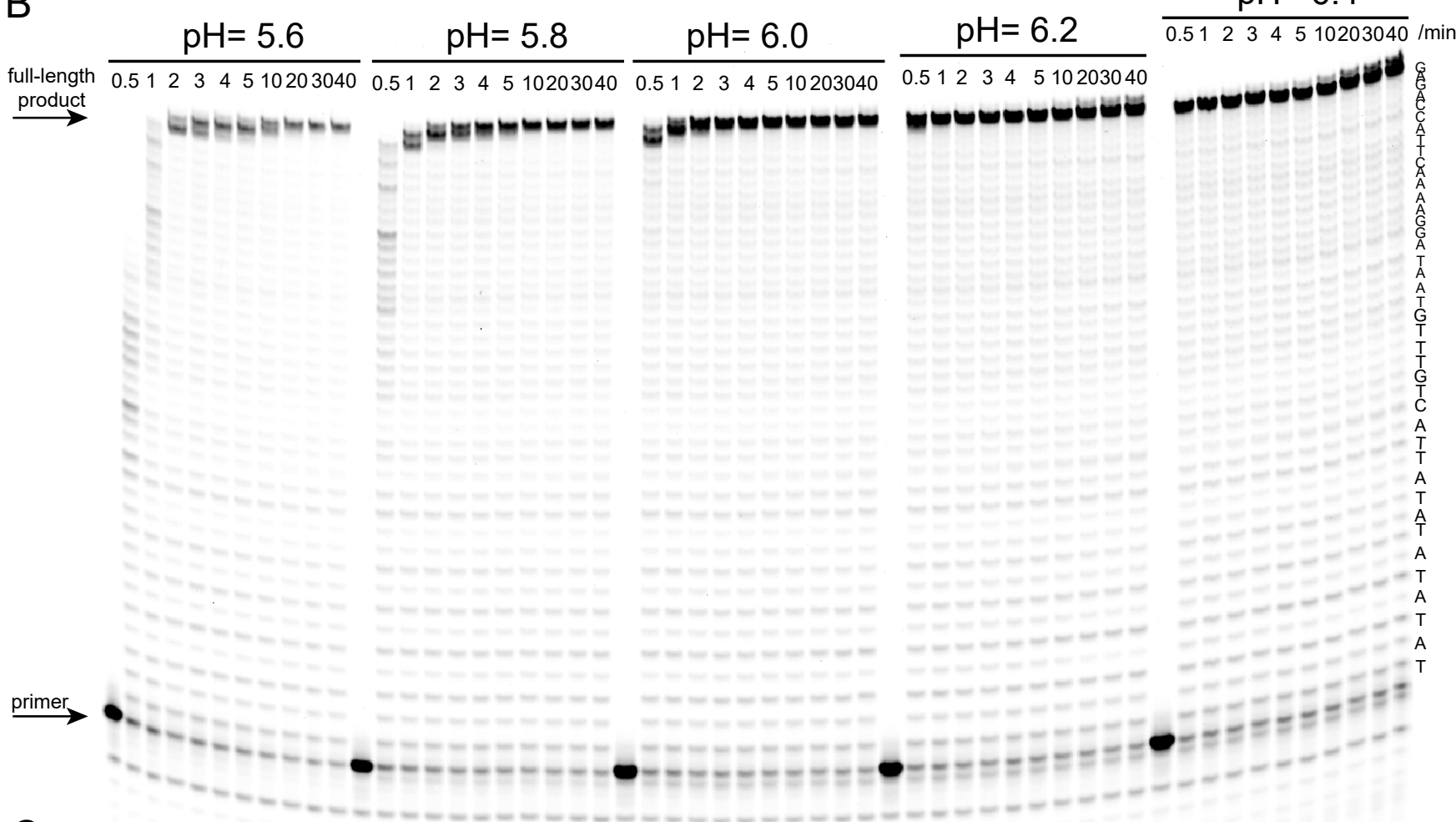

C

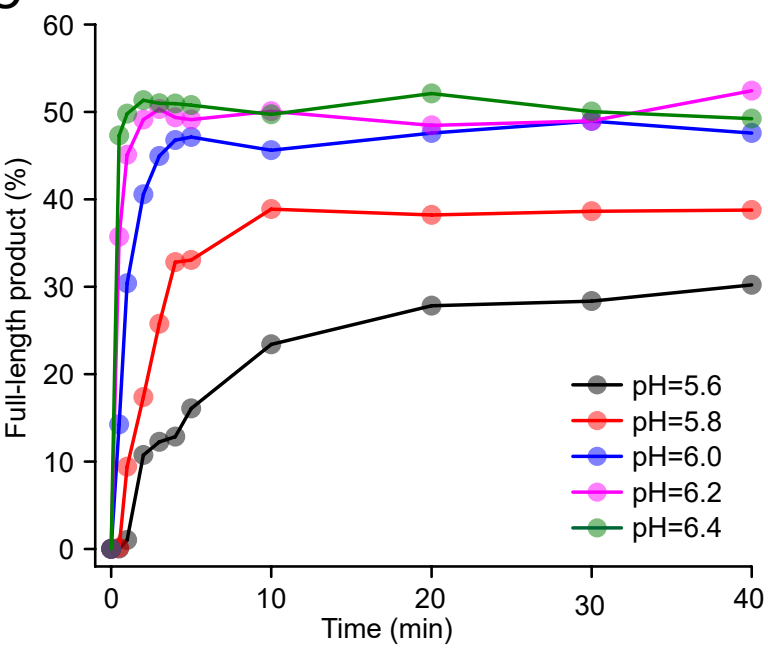

Figure S6. Non-iM control DNA with no secondary DNA structures allow DNA synthesis in $\mathrm{pH}=5.6-6.4$. Sequence $(A)$ and representative sequencing gel $(B)$ of primer extension assay with ssDNA template (non-iM) sequence. $\mathrm{pH}$ of the reaction is written above each gel. Time-points when individual samples were collected is written above each well. Quantification of full-length product is describing an effect of $\mathrm{pH}$ on overall reaction. 
biARxiv preprint doi: Bttpsffdgi-org/10.1101/2022.01.05.475026; this ver勋n posted January 5 2022 The gopyright holder for this preprint

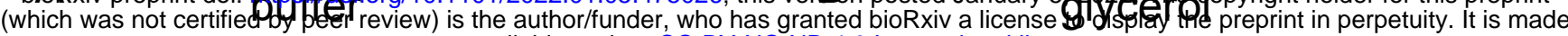

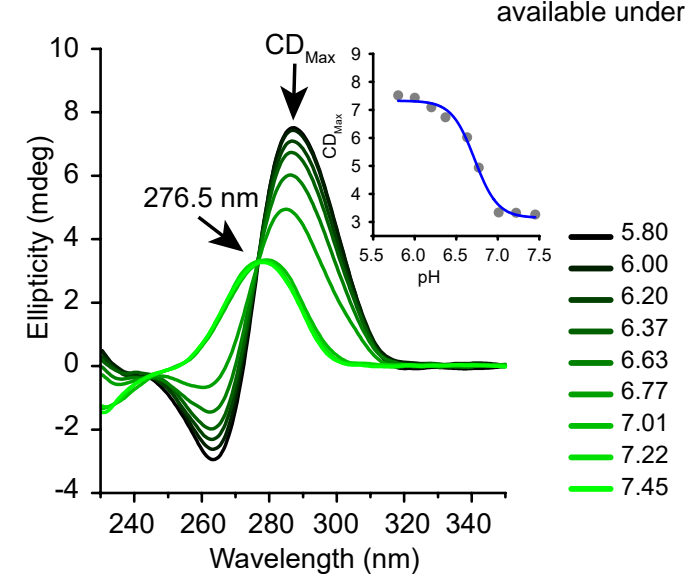

C

PEG1000

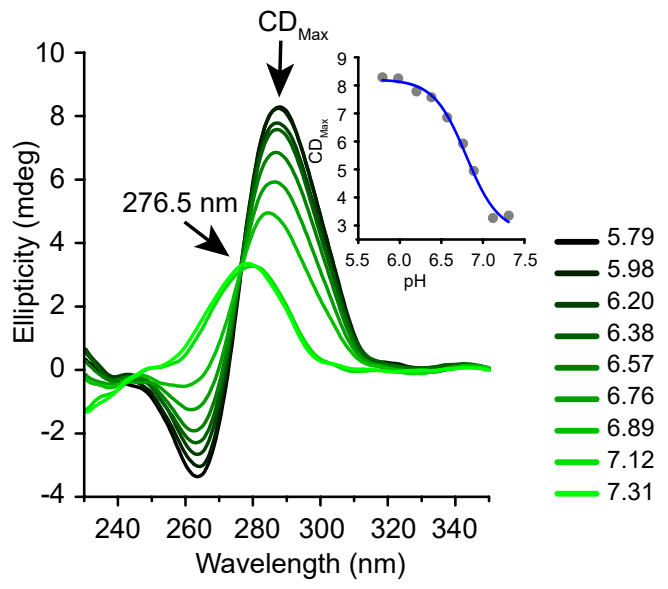

$\mathrm{E}$

dextran40

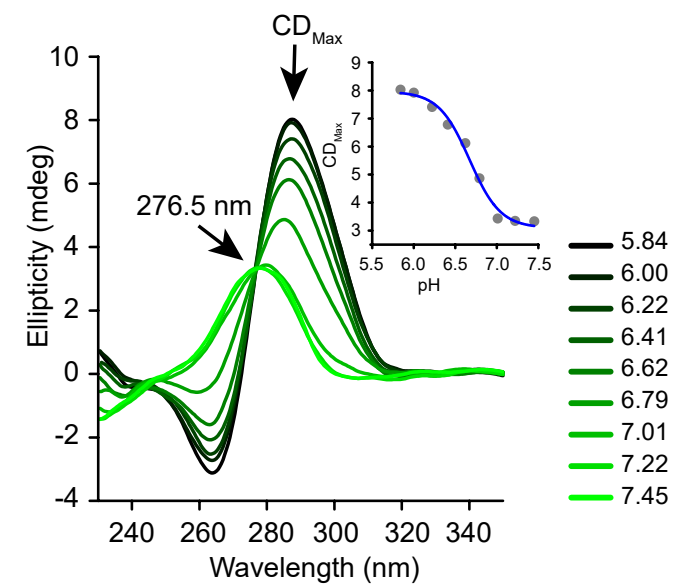

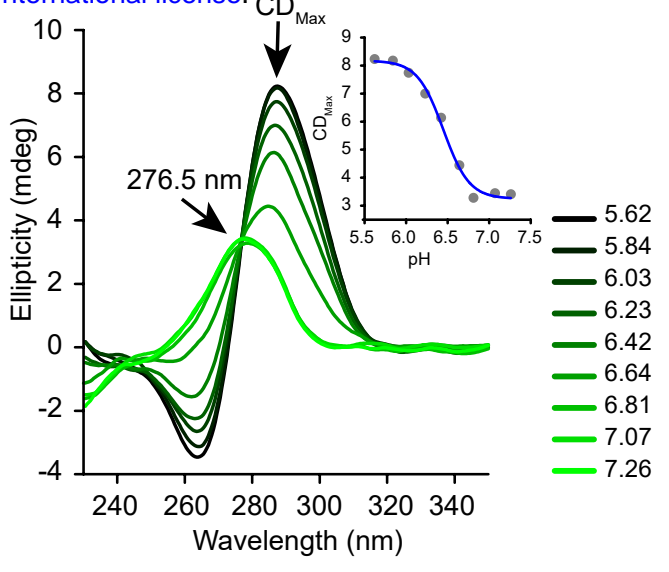

D

PEG8000

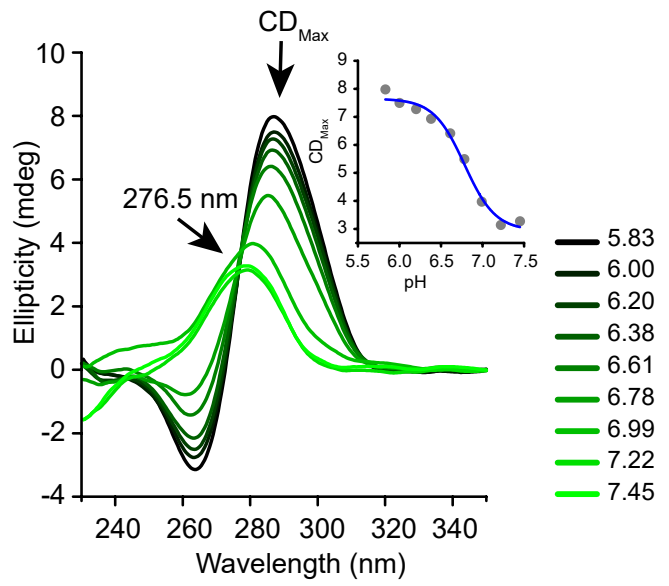

$\mathrm{F}$

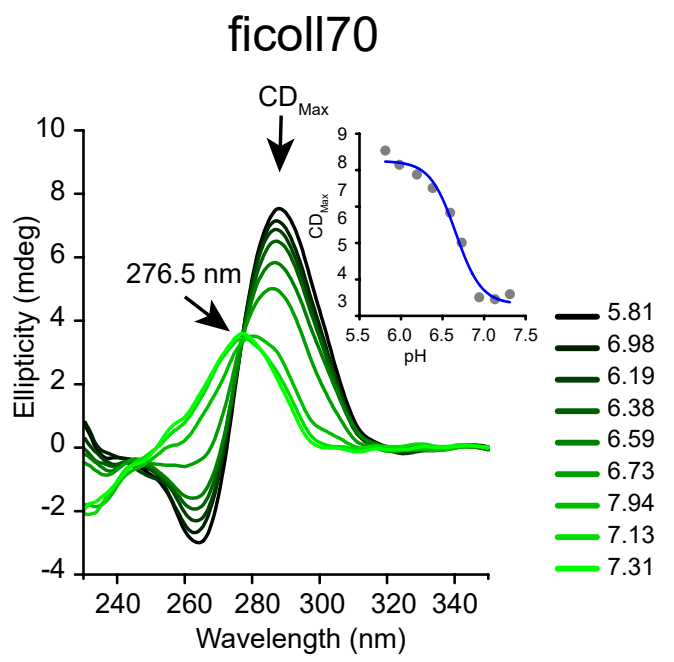

Figure S7. Molecular crowders and co-solutes do not shift pKa of Jazf1 iM into neutral pH. Individual CD spectra of Jazf1 iM in the presence of $20 \%$ co-solutes and molecular crowders: no additives (A), glycerol (B), PEG1000 (C), PEG8000 (D), dextran40 (E) and ficoll70 (F). CD spectra were recorded at $25^{\circ} \mathrm{C}$ in different $\mathrm{pH} . \mathrm{CD}_{\max }$ values were plotted against $\mathrm{pH}$ and $\mathrm{pH}_{\mathrm{T}}$ values were calculated by fitting the data into dose-response function (embedded graphs in each $C D$ plot). $\mathrm{pH}_{\mathrm{T}}$ values are graphically shown in Figure 1. 


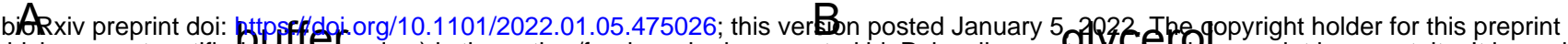

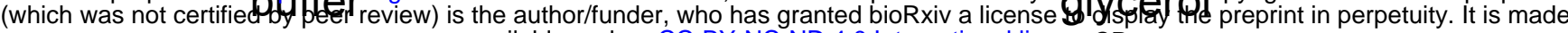

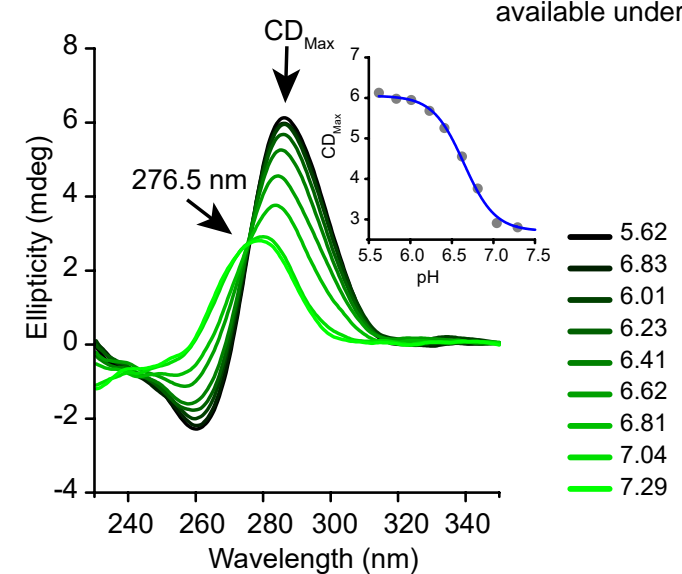

C

PEG1000
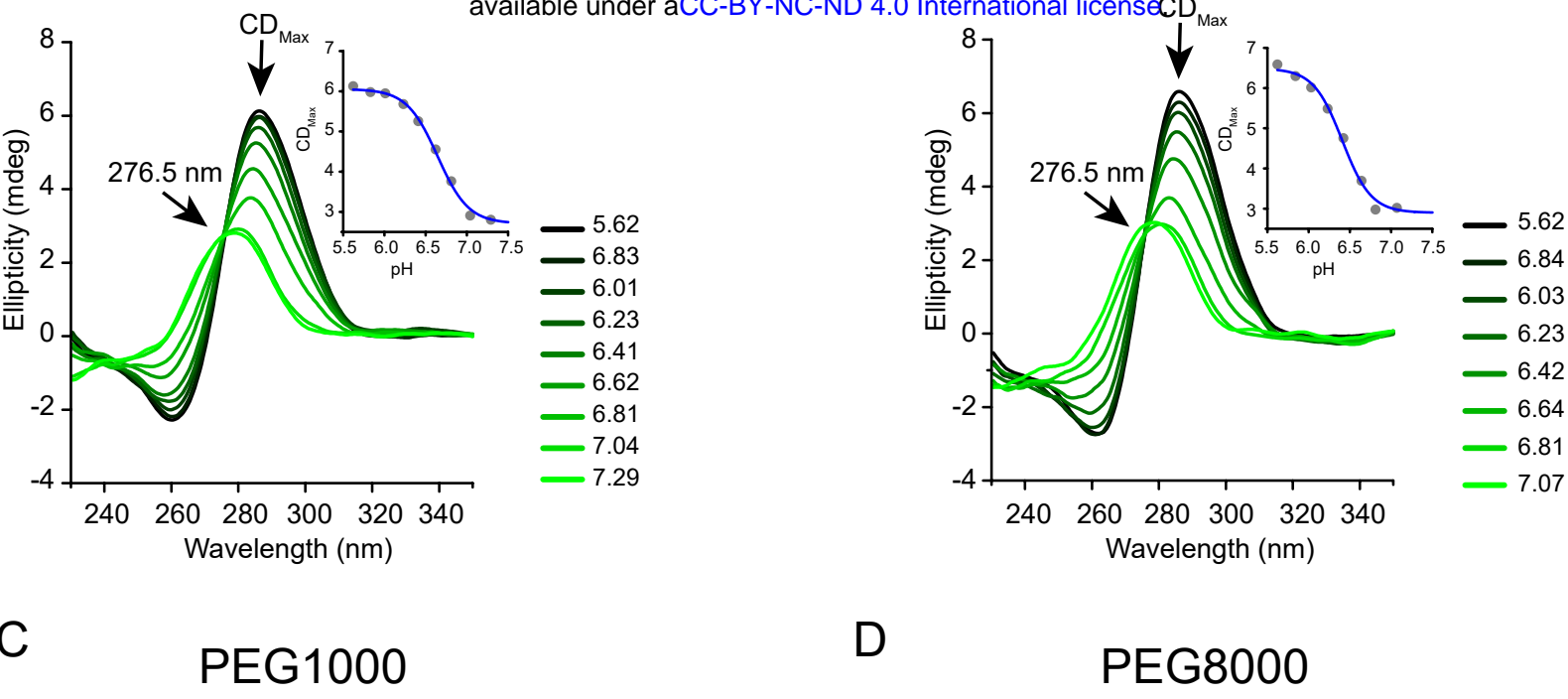

D

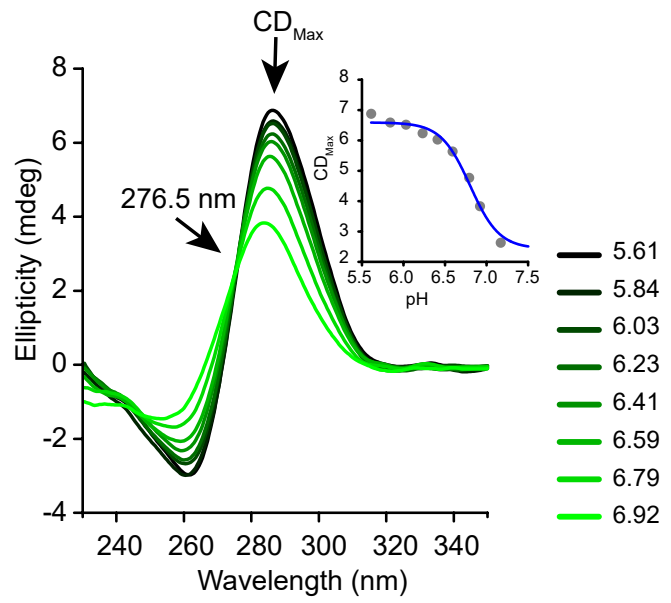

$\mathrm{E}$

dextran40

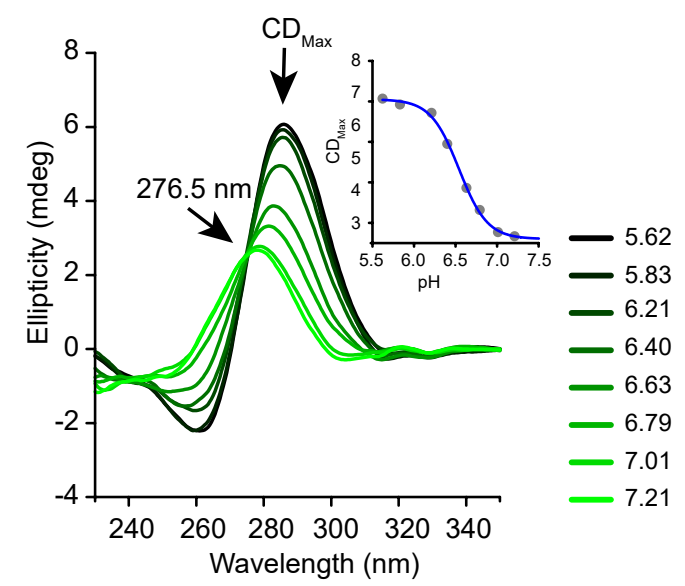

$\mathrm{F}$

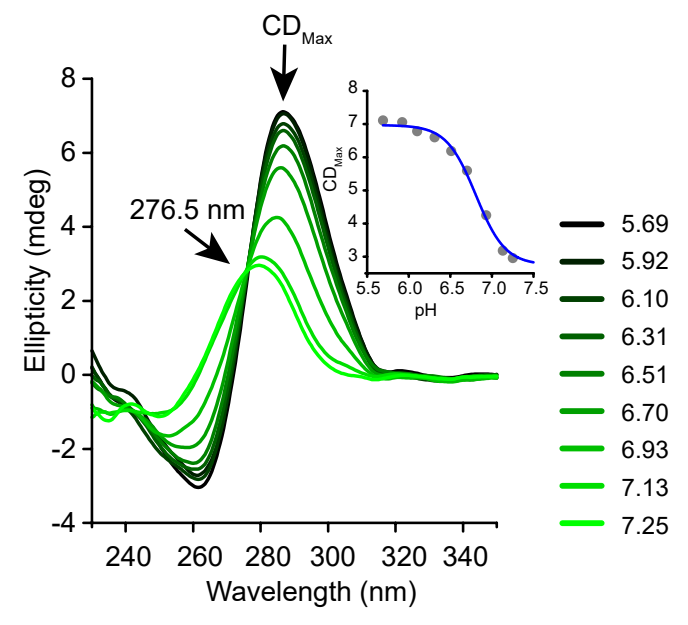

\section{ficoll70}

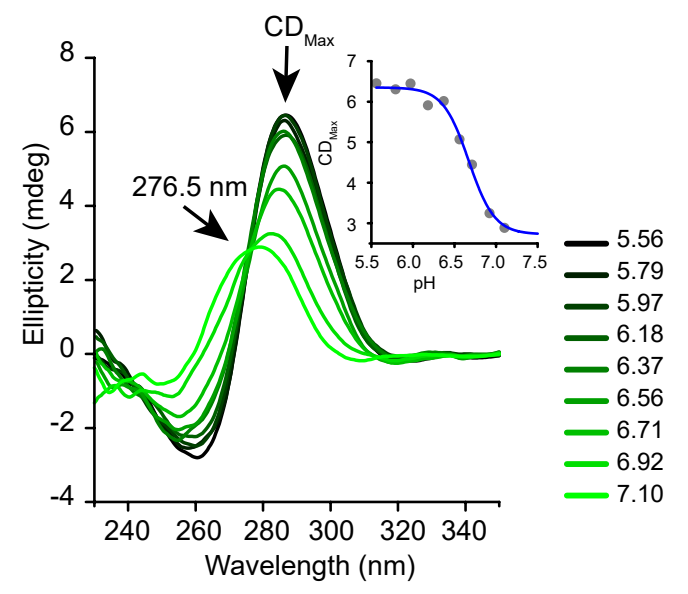

Figure S8. Molecular crowders and co-solutes do not shift pKa of Hif-1 $\alpha$ iM into neutral pH. Individual CD spectra of Jazf1 iM in the presence of $20 \%$ co-solutes and molecular crowders: no additives (A), glycerol (B), PEG1000 (C), PEG8000 (D), dextran40 (E) and ficoll70 (F). CD spectra were recorded at $25^{\circ} \mathrm{C}$ in different $\mathrm{pH} . \mathrm{CD}_{\max }$ values were plotted against $\mathrm{pH}$ and $\mathrm{pH}_{\mathrm{T}}$ values were calculated by fitting the data into dose-response function (embedded graphs in each $\mathrm{CD}$ plot). $\mathrm{pH}_{\mathrm{T}}$ values are graphically shown in Figure 1. 
A

bioRxiv preprint doi: https://doi.org/10.1101/2022.01.05.475026; this version posted January 5, 2022. The copyright holder for this preprint

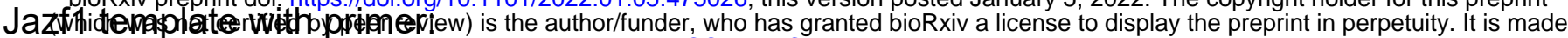
available under $\underset{* \star *}{a}$ C-BY-NC-ND 4.0 International license.

5' CCCCCCCCGCCCCCGCCCCCGCCCTCCCCCCatatatatatCGGACGCTCGACGCCATTAATAATGTTTTCA 3'

$5 \frac{3}{3} \frac{3}{2} \frac{3}{1} \quad$ GCCTGCGAGCTGCGGTAATTATTACAAAAGT 5'

B

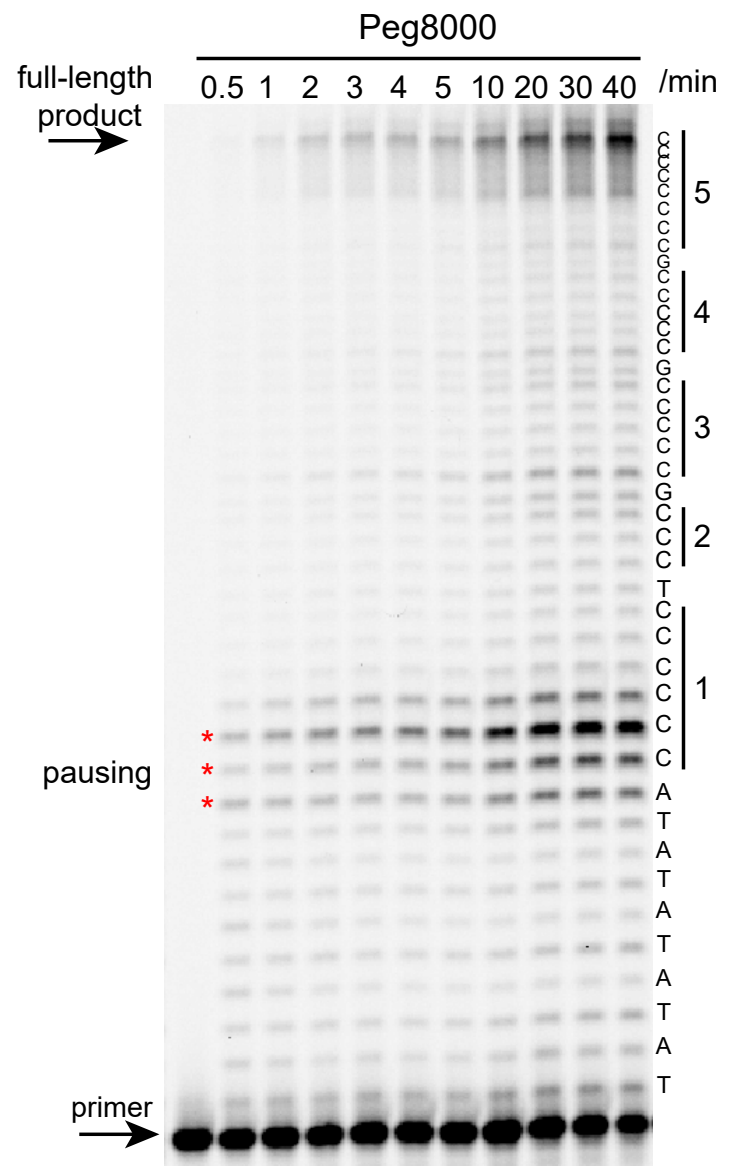

D

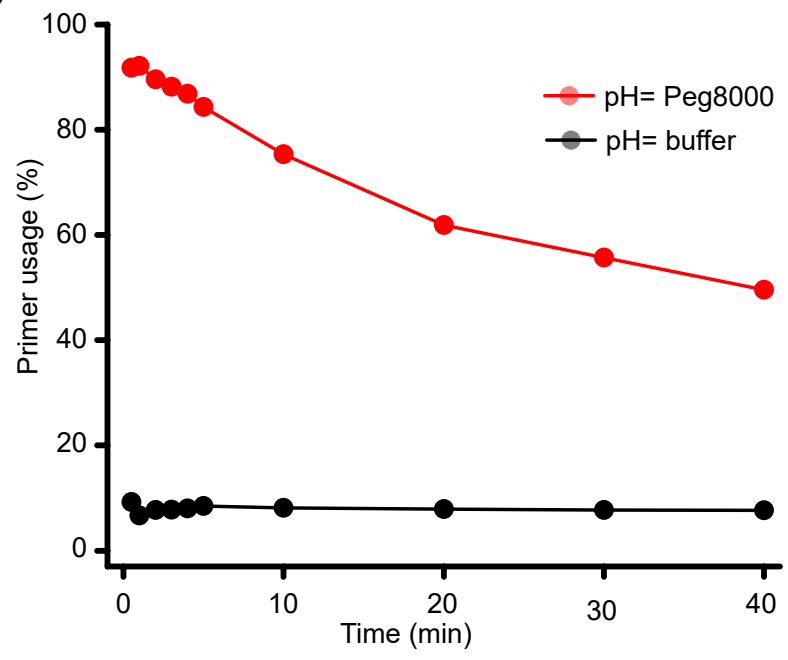

C

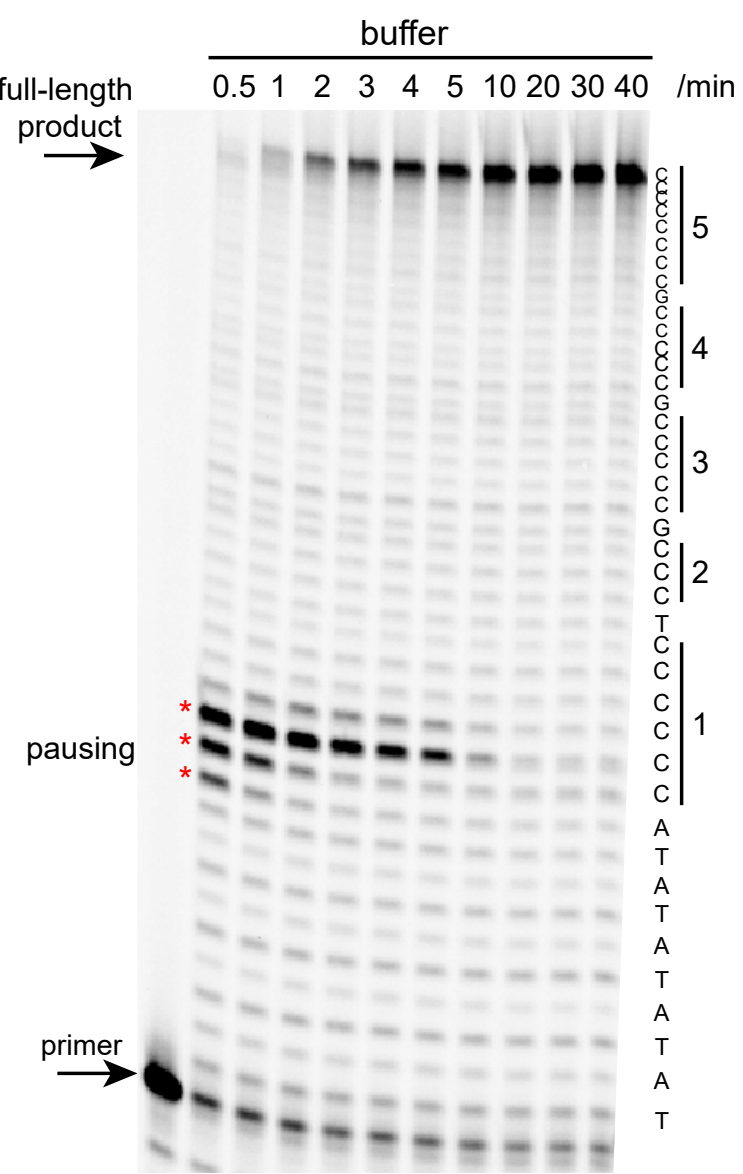

Figure S9. $20 \%$ PEG 8000 inhibits primer extension assay in an unspecific and non-iM dependent manner. Jazf1 sequence $(A)$ and a sequencing gel $(B)$ of primer extension assay supplemented with $20 \%$ PEG8000 and (C) with no supplements. Time-points when individual samples were collected is written above each well. C-tracts from iM sequence are underlined in $\mathrm{A}$ and depicted on the right side of the gel in $B$ and $C$. Pausing site is depicted as red stars $\left({ }^{* * *}\right)$ in each reaction and shown also in A. Pausing site appearing in 10-40 minutes of reaction with PEG8000 cannot be a consequence of stabilized iM, but rather it is caused by very slow reaction initiation. D) Quantification of primer consumption from gels in $B$ and $C$ between $0.5-40$ minutes. 
A

bioRxiv preprint doi: httpș://doi.org/10.1101/2022.01.05.475026; this version posted January 5, 2022. The copyright holder for this preprint Dapuitiempadatecutitied (pripee review) is the author/funder, who has granted bioRxiv a license to display the preprint in perpetuity. It is made available under aCC-BY-NC-ND 4.0 International license.

5' CCCCCGCCCCCGCCCCCGCCCCCGCCCCCatatatatatCGGACGCTCGACGCCATTAATAATGTTTTCA 3'
5
4
3
3' GCCTGCGAGCTGCGGTAATTATTACAAAAGT 5'

B

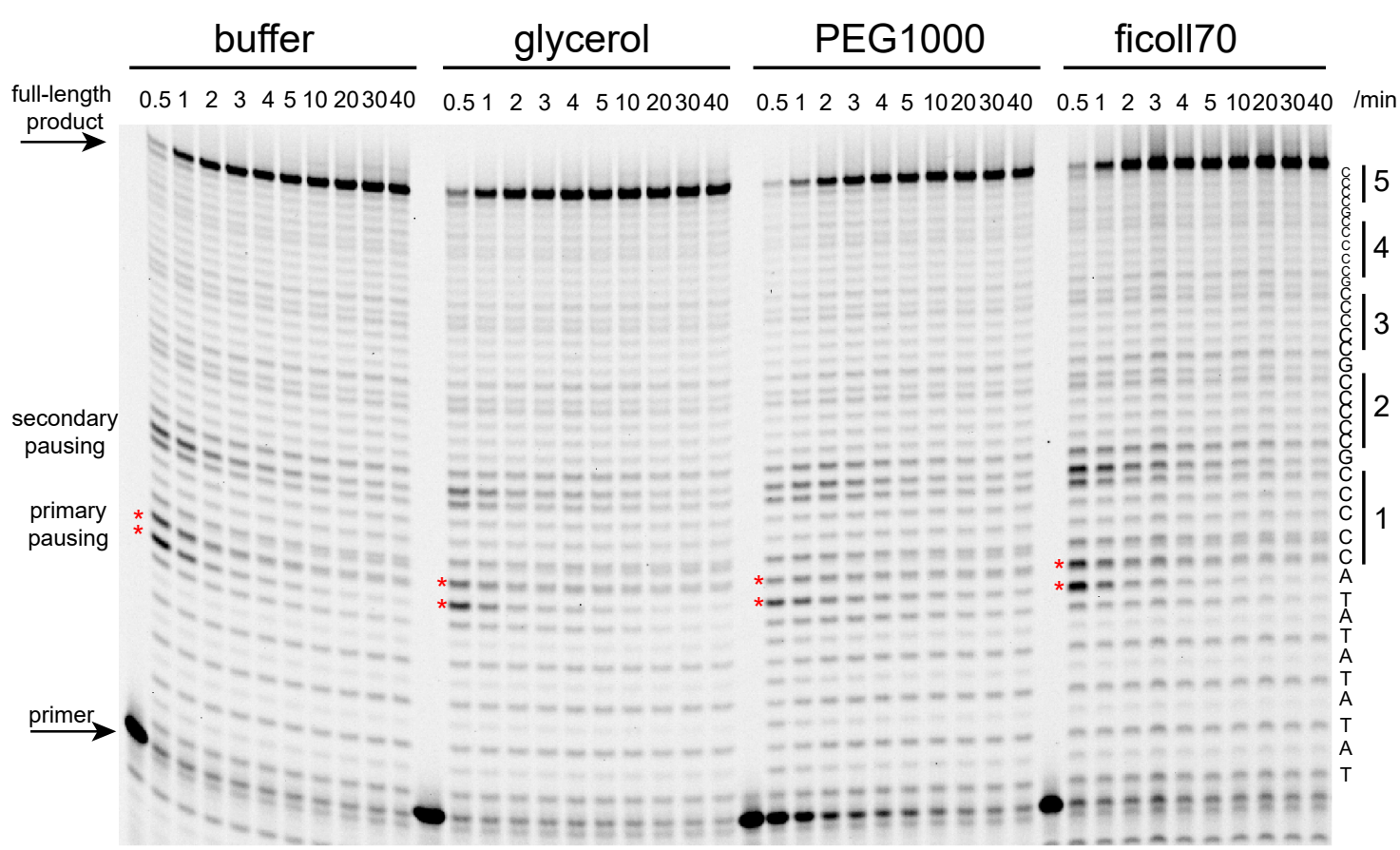

C
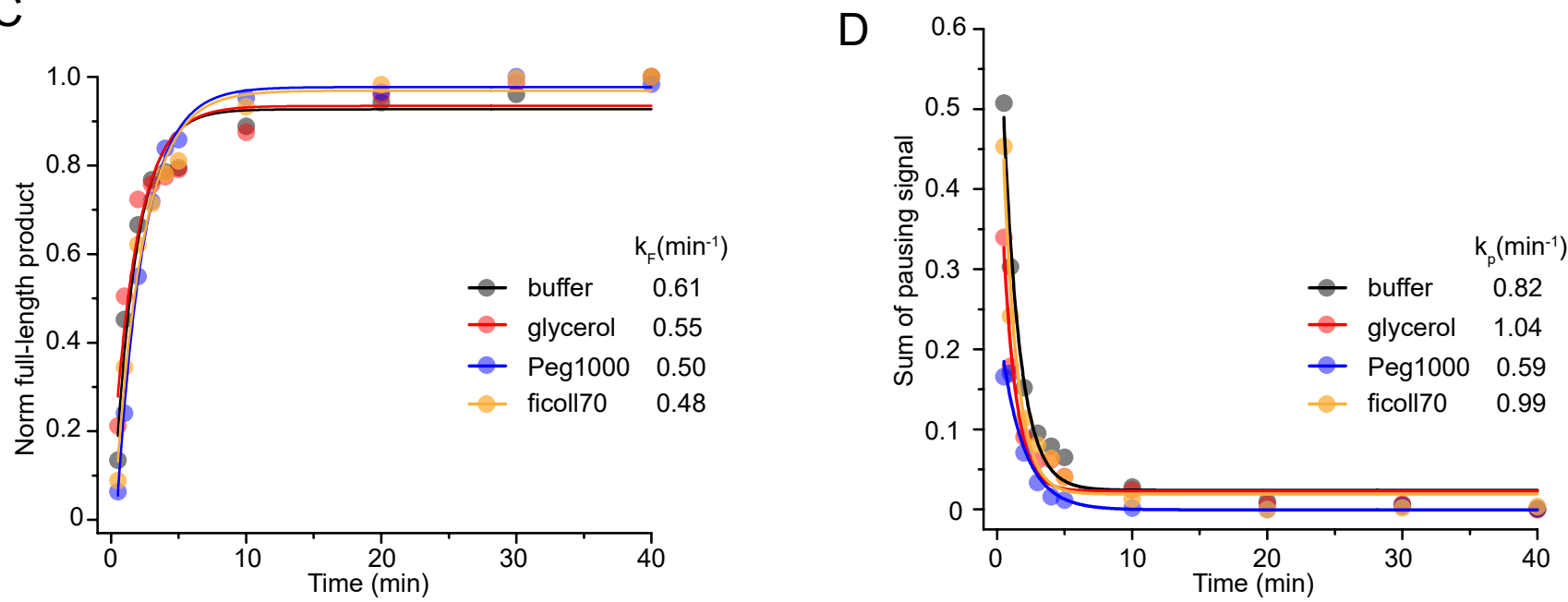

Figure S10. Molecular crowders and co-solutes do not stabilize Dap iM in primer extension assay in $\mathbf{p H}=6$. Sequence $(A)$ and representative sequencing gel $(B)$ of primer extension assay with template containing Dap iM sequence run at $37{ }^{\circ} \mathrm{C}$. Reactions were supplemented with $20 \%$ of cosolutes or molecular crowders. Specific condition is written above each gel. Time when individual samples were collected is written above each well. C-tracts from iM sequence are underlined in $\mathrm{A}$ and depicted on the right side of the gel. Pausing site is depicted as red stars $\left({ }^{* *}\right)$ in each reaction and shown also in A. Quantification of full-length product (C) and pausing signal (D) of each reaction is describing an effect of additives on overall reaction and $\mathrm{iM}$, respectively. Data from individual reactions are fitted into exponential equation in OriginLab software and apparent rate constants $\mathrm{k}_{\mathrm{F}}$ and $\mathrm{k}_{\mathrm{P}}$ are shown in $\mathrm{C}$ and $\mathrm{D}$. 
A

bioRxiv preprint doi: https://doi.org/10.1101/2022.01.05.475026; this version posted January 5, 2022. The copyright holder for this preprin

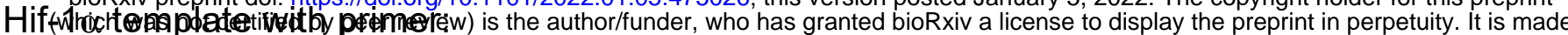
available under aCC-BY-NC-ND 4.0 International license.

5'CGCGCTCCCGCCССCTCTCCCCTCCCCGCGCCatatatatCGGACGCTCGACGCCATTAATAATGTTTTCA 3'

B

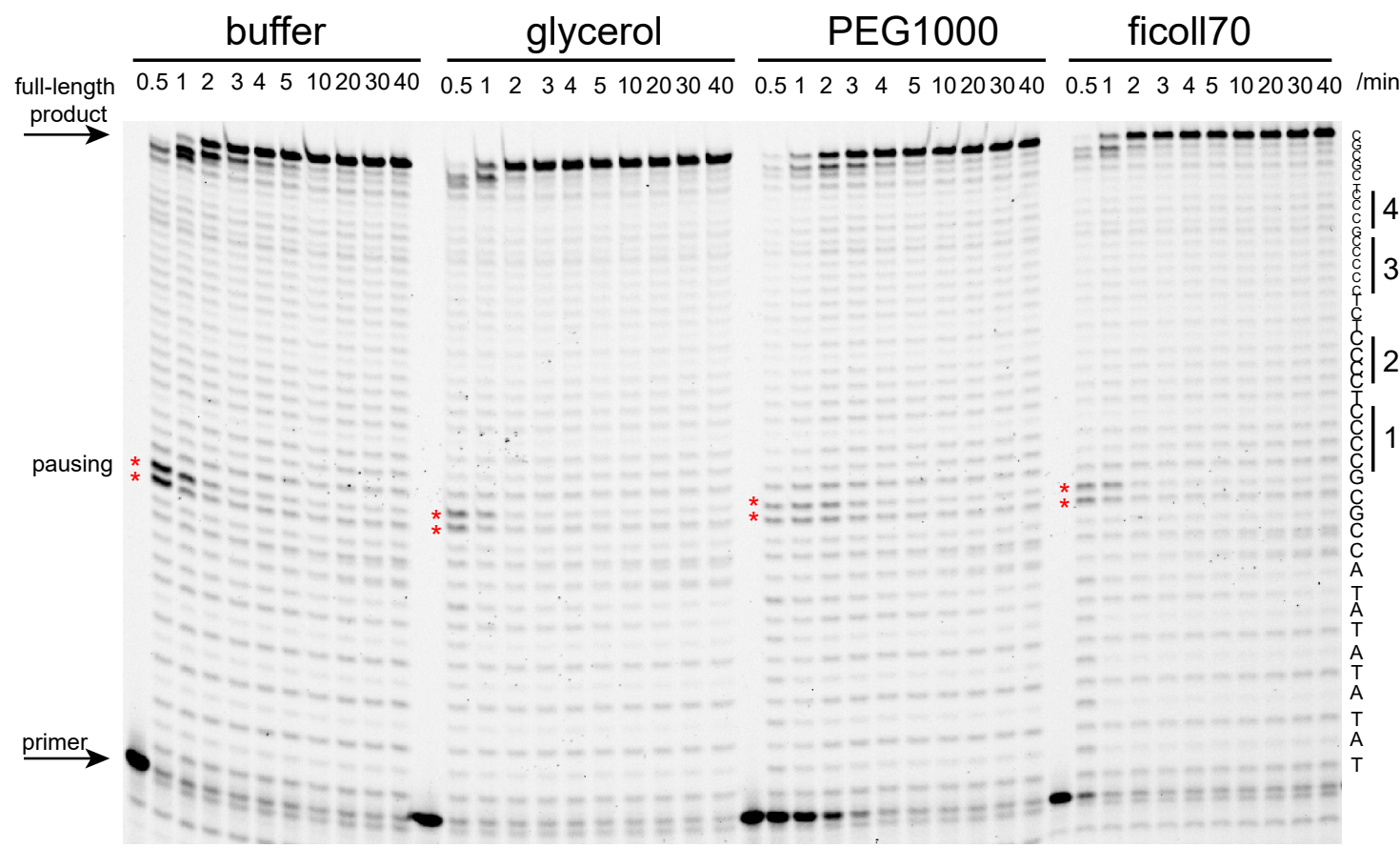

C
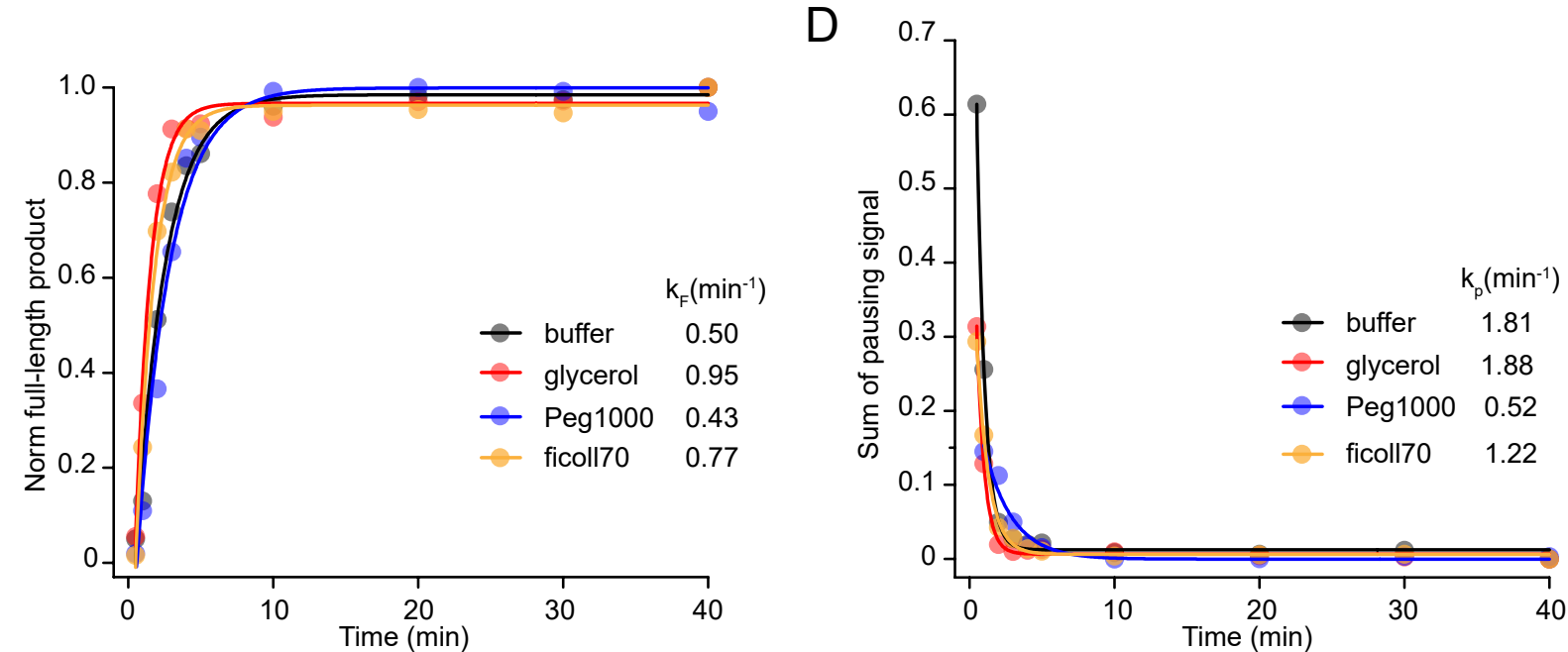

Figure S11. Molecular crowders and co-solutes do not stabilize Hif-1 $\alpha$ iM in primer extension assay in $\mathbf{p H}=6$. Sequence $(A)$ and representative sequencing gel $(B)$ of primer extension assay with template containing Hif- $\alpha$ iM sequence run at $37^{\circ} \mathrm{C}$. Reactions were supplemented with different cosolutes and molecular crowders. Specific condition is written above each gel. Time-points when individual samples were collected are written above each well. C-tracts from iM sequence are underlined in A and depicted on the right side of the gel. Pausing site is depicted as red stars $\left({ }^{* *}\right)$ in each reaction and shown also in A. Quantification of full-length product (C) and pausing signal (D) of each reaction is describing an effect of additives on overall reaction and IM, respectively. Data from individual reactions are fitted into exponential equation in OriginLab software and apparent rate constants $\mathrm{k}_{\mathrm{F}}$ and $\mathrm{k}_{\mathrm{P}}$ are shown in $\mathrm{C}$ and $\mathrm{D}$. 
A

bioRxiv preprint doi: https://doi.org/10.1101/2022.01.05.475026; this version posted January 5, 2022. The copyright holder for this preprint Jazthighwasnotcertifieqbopeer revjew) is the author/funder, who has granted bioRxiv a license to display the preprint in perpetuity. It is made available under aCC-BY-NC-ND 4.0 International license.

5' CCCCCCCCGCCCCCGCCCCCGCCCTCCCCCªtatatatatCGGACGCTCGACGCCATTAATAATGTTTTCA 3'
5
4
$3 \quad \frac{1}{2}$
3' GCCTGCGAGCTGCGGTAATTATTACAAAAGT 5'

B

non-iM template with primer:

5’ GAGACCATTCAAAAGGATAATGTTTGTCATTatatatatatCGGACGCTCGACGCCATTAATAATGTTTTCA 3'

3' GCCTGCGAGCTGCGGTAATTATTACAAAAGT 5'

C

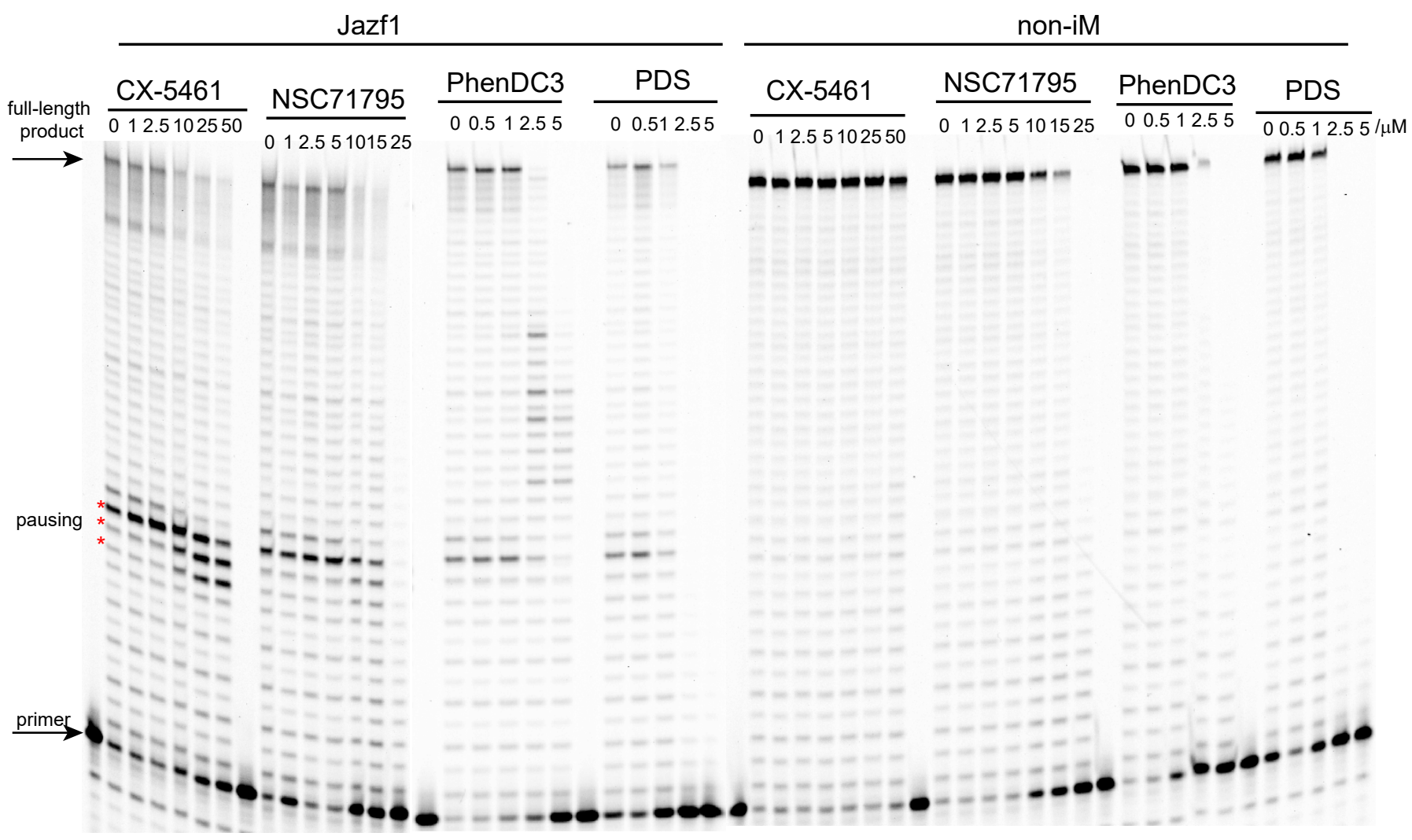

Figure S12. CX-5461 identified as a potential iM stabilizer in high resolution primer extension assay. Drug screening of sequences $(A, B)$ and representative sequencing gel $(C)$ of primer extension assay with templates containing Jazf1 iM and Non-iM sequence run for 4 min at $37^{\circ} \mathrm{C}$. Reactions were supplemented with various concentrations of small molecules (CX-5461, NSC71795, PhenDC3, Pyridostatin-PDS), described above each gel. C-tracts from iM sequence are underlined in A. Pausing site is depicted as red stars $\left(^{* * *}\right)$ in $(A)$ and $(C)$. 
A

bioRxiv preprint doi:https://doi.org/10.1101/2022.01.05.475026; this version posted January 5, 2022. The copyright holder for this preprint Jazfwidiemaphatertkithbjofieneriew) is the author/funder, who has granted bioRxiv a license to display the preprint in perpetuity. It is made available under aCC-BY-NC-ND 4.0 International license.

5' CCCCCCCCGCCCCCGCCCCCGCCCTCCCCCCatatatatatCGGACGCTCGACGCCATTAATAATGTTTTCA 3'
5
4
$3 \frac{1}{2}$
3' GCCTGCGAGCTGCGGTAATTATTACAAAAGT 5'

B

non-I-motif template with primer:

5' GAGACCATTCAAAAGGATAATGTTTGTCATTatatatatatCGGACGCTCGACGCCATTAATAATGTTTTCA 3' 3' GCCTGCGAGCTGCGGTAATTATTACAAAAGT 5'

C Jazf1

non-iM

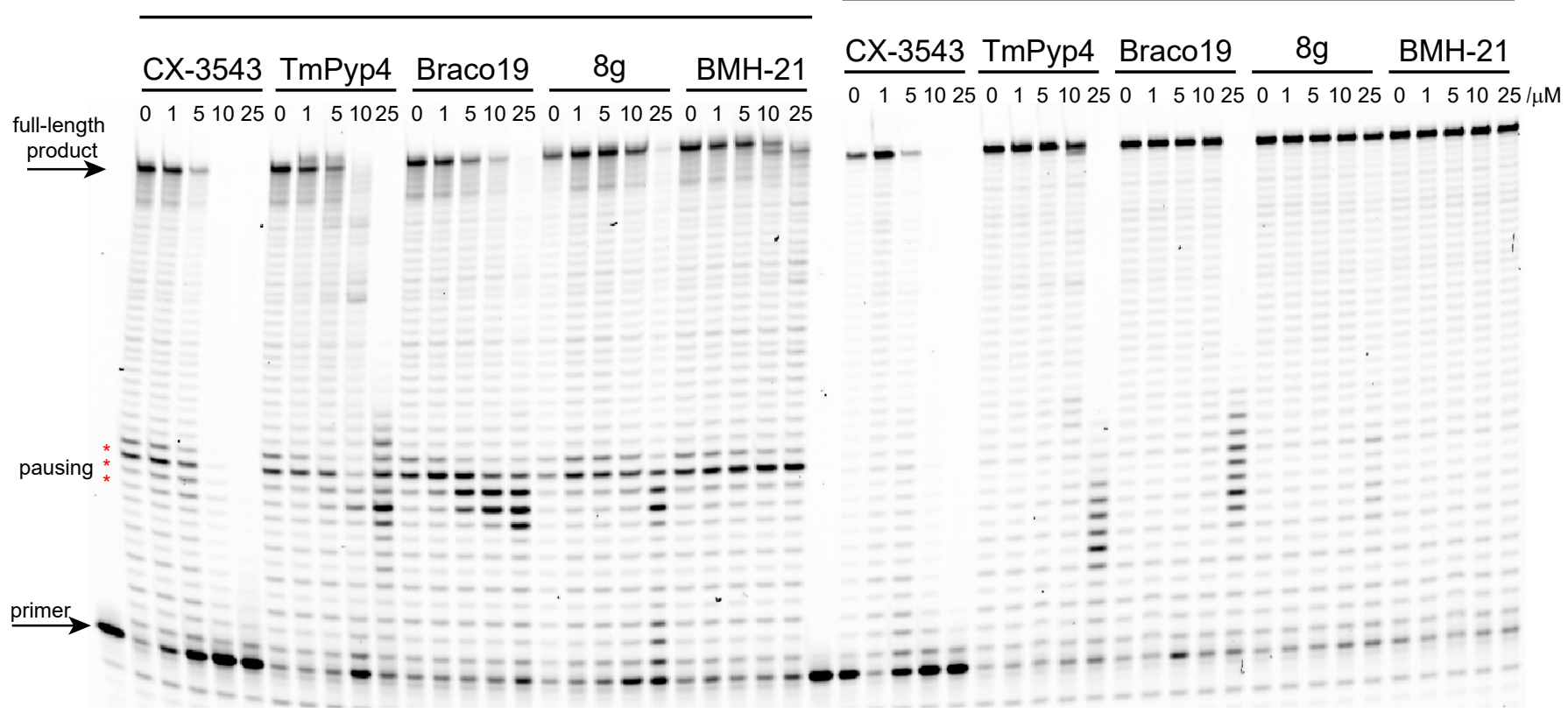

Figure S13. Ligands in high resolution primer extension assay. Sequences (A, B) and representative sequencing gel $(C)$ of primer extension assay with templates containing Jazf1 iM and Non-iM sequence run for $4 \mathrm{~min}$ at $37^{\circ} \mathrm{C}$. Reactions were supplemented with various concentrations of small molecules (CX-3543, TmPyP4, Braco19, quinazoline $8 \mathrm{~g}$ and BMH-21), described above each gel. C-tracts from iM sequence are underlined in A. Pausing site is depicted as red stars $\left.{ }^{(* *}\right)$ in $(A)$ and $(C)$. 